\title{
Cyclization Reactions for the Synthesis of Phthalans and Isoindolines
}

\author{
Gianluigi Albano \\ Laura Antonella Aronica * \\ ${ }^{a}$ Department of Chemistry and Industrial Chemistry, \\ University of Pisa, Via G. Moruzzi 13, 56124 Pisa, Italy. \\ Laura.Antonella.Aronica@unipi.it
}

This is the accepted version of an article published in its final forma at

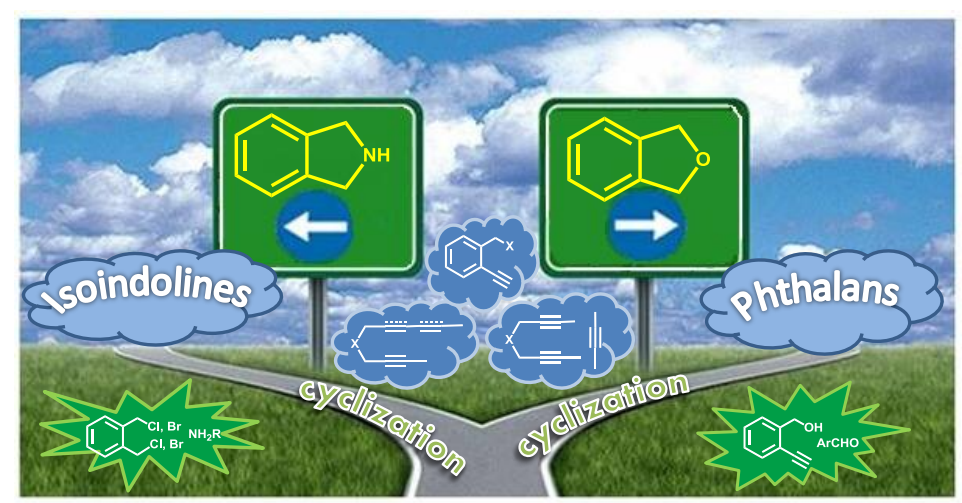

https://www.thieme-connect.de/products/ ejournals/abstract/10.1055/s-0037-1609175

(c) Georg Thieme Verlag

\begin{tabular}{|c|c|}
\hline \multicolumn{2}{|c|}{$\begin{array}{l}\text { Received: } \\
\text { Accepted: } \\
\text { Published online: } \\
\text { DOI: }\end{array}$} \\
\hline \multicolumn{2}{|c|}{$\begin{array}{l}\text { Abstract Oxygen and Nitrogen-heterocyclic compounds are present in a vast } \\
\text { number of natural substrates and biologically active molecules. In particular, } \\
\text { phthalan and isoindoline subunits are found in many classes of products such } \\
\text { as antibiotics, antioxidants, antimicotics, pigments and fluorophores. } \\
\text { Therefore several procedure dedicated to the construction of these } \\
\text { heterocycles have been developed. In this review a detailed analysis of } \\
\text { literature data regarding the synthesis of these nuclei via cyclization reactions } \\
\text { is reported. }\end{array}$} \\
\hline 1 & Introduction \\
\hline 2 & Phthalans \\
\hline & Oxa-Pictet-Spengler reaction \\
\hline & Garratt-Braverman cyclization \\
\hline & Diels-Alder and related reactions \\
\hline & {$[2+2+2]$ Cyclotrimerization of alkynes } \\
\hline & Cycloetherification of ortho-substituted aromatics \\
\hline & Tandem carbonylative Sonogashira-cyclization reaction \\
\hline 3 & Isoindolines \\
\hline & Amination of dihalides \\
\hline & Intramolecular Hydroamination \\
\hline & Diels Alder and related reactions \\
\hline & {$[2+2+2]$ Cyclotrimerization of alkynes } \\
\hline & Tandem carbonylative Sonogashira-cyclization reaction \\
\hline & $\begin{array}{l}\text { s phthalan, isoindoline, cyclization, transition metal catalysis, } \\
\text { ra reaction }\end{array}$ \\
\hline
\end{tabular}

\section{Introduction}

The chemistry of oxygen and nitrogen-containing heterocycles has attracted much attention in recent times due to its increasing importance in the fields of pharmaceutical compounds and industrial chemicals. In particular, phthalan (1,3-dihydoisobenzofuran) and isoindoline (Figure 1) subunits are present in many classes of products. For instance, phthalan moiety has been found in pestacin (Figure 2 A), isolated in 2003 by Grant et al. from Pestalotiopsis microspora, and revealed good antimycotic and antioxidant properties. ${ }^{1}$ Many synthetic phthalans showed remarkable pharmacological activities: citalopram (Figure 2 B) developed in 1989, is a serotonine reuptake inhibitor used in the treatment of depressive syndromes and anxiety disorders. ${ }^{2}$

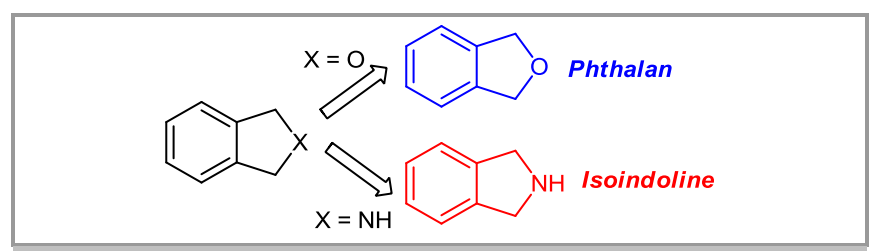

Figure 1 Phthalan and isoindolines structures.

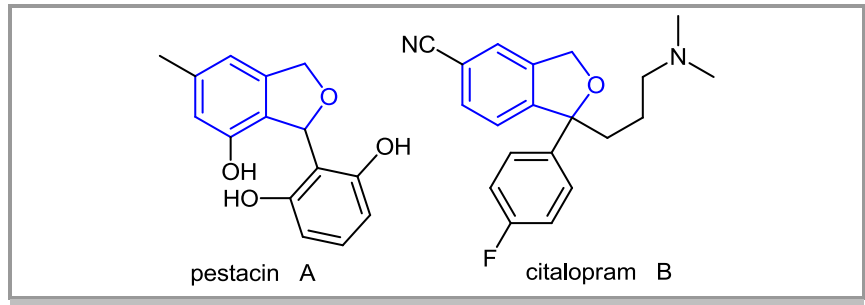

Figure 2 Chemical structure of bioactive phthalans: pestacin (A), citalopram (B).

Analogously, several isoindoline derivatives act as efficient enzymatic inhibitors, ${ }^{3}$ display antipsychotic activity, ${ }^{4}$ and show citotoxicity against human colon and cervical cancer cells ${ }^{5}$ (Figure 3). Besides, isoindoline diyilidene-based compounds are the nuclei of pigments which cover the range from greenish yellow to orange, red and brown. ${ }^{6}$

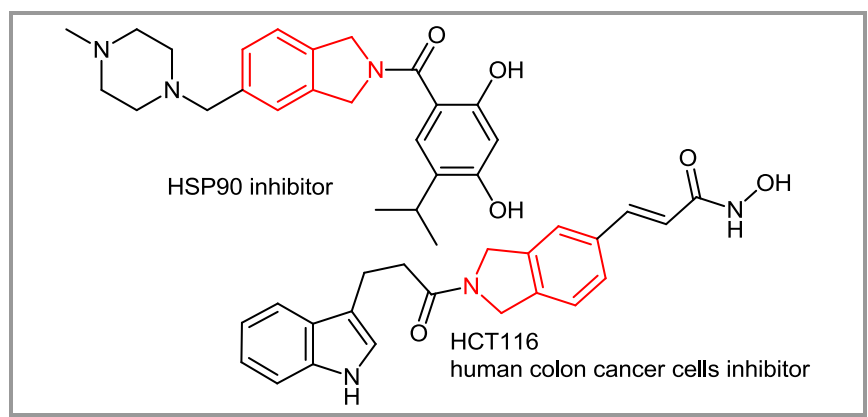

Figure 3 Examples of isoindolines-based biologically active compounds. 
From the point of view of chemical reactivity, both phthalans and isoindolines are powerful building blocks for the syntheses of numerous classes of compounds: benzylic alcohols ${ }^{7}$ and amines $^{8}$ (Scheme 1, a, b), isoquinolin-1(2H)-ones (Scheme 1, c), ${ }^{9}$ phenanthro[10,1-bc] furans (Scheme 1, d), ${ }^{10}$ pyrazoles (Scheme 1, e), ${ }^{11}$ isochroman-3-ones (Scheme 1,f), ${ }^{7}$ isoindoles (Scheme 1, g), ${ }^{12}$ and isoindolinones (Scheme $\left.1, \mathrm{~h}\right){ }^{13}$

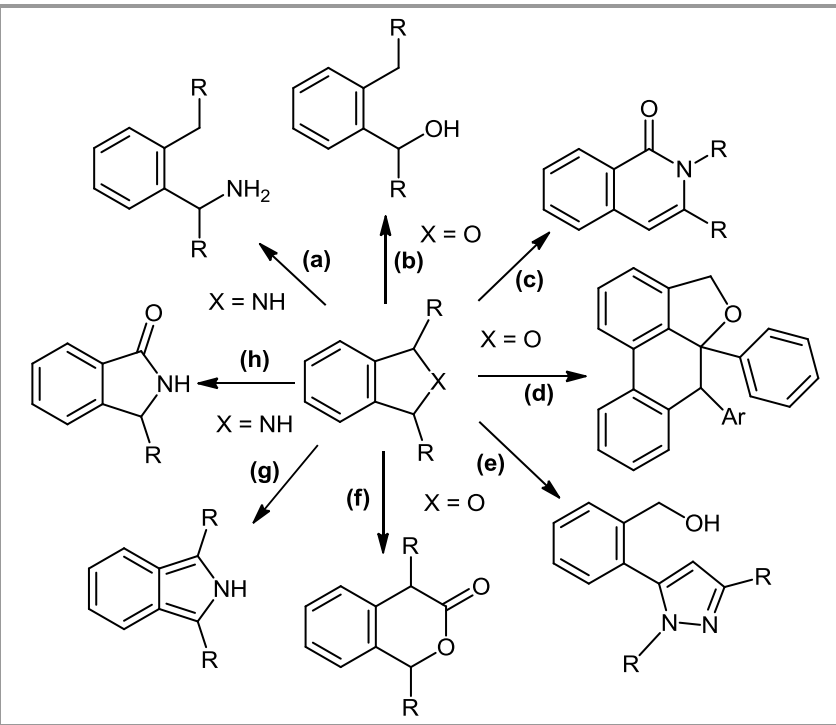
Scheme 1 Chemical reactivity of phthalans and isoindolines.

Several procedures dedicated to the construction of such heterocycles have been developed. Many of them are based on the cyclization of suitable substrates. This review is focused on the principal cyclization-based routes to the formation of phthalans and isoindolines nuclei. In particular the literature regarding each heterocycle has been organised in two chapters which have been divided into sections concerning a specific synthetic method.

\section{Phthalans}

Several procedures for phthalans synthesis based on cyclization strategies have been described in the literature, including a very large number of substrates, reactants and conditions. However, they can be grouped in the following sections, discussed below: a) oxa-Pictet-Spengler reaction; b) Garratt-Braverman cyclization; c) Diels-Alder and related reactions; d) $[2+2+2]$ cyclotrimerization of alkynes; e) cycloetherification of ortho-substituted aromatics; f) cyclocarbonylative Sonogashira reaction.

\subsection{Oxa-Pictet-Spengler reaction}

Widely used for obtaining isochroman systems, ${ }^{14}$ the oxa-PictetSpengler reaction has also found application in the synthesis of several polysubstituted phthalans (Scheme 2).<smiles>[R]c1cc([R])cc(CO)c1</smiles>

Scheme 2 Phthalans synthetic strategy by oxa-Pictet-Spengler reaction.
The first work was reported by Marra et al., which described the preparation of hydroxyphthalans 5 by acid-catalyzed condensation of benzyl alcohols $\mathbf{3}$ with 3,4,5-trisubstituted benzaldehydes $\mathbf{4}$ in methanol as solvent (Scheme 3). ${ }^{15}$

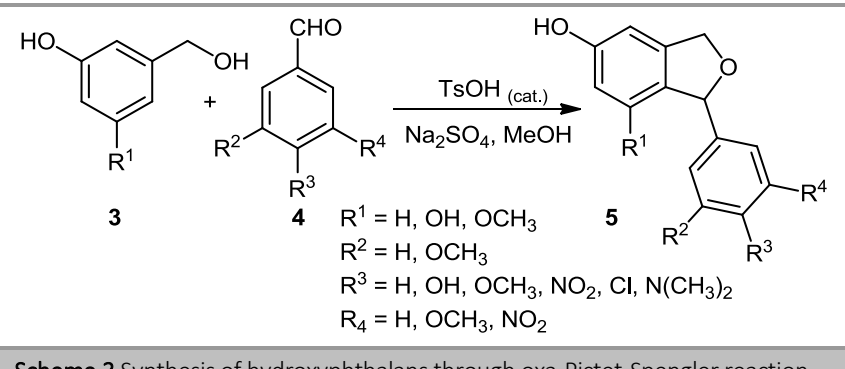

Scheme 3 Synthesis of hydroxyphthalans through oxa-Pictet-Spengler reaction.

More recently, Khosropour and coll. developed a new protocol, consisting in the use of nanosilica sulfuric acid (NSSA), obtained by adding chlorosulfonic acid to nano- $\mathrm{SiO}_{2}$ at room temperature, as reusable heterogeneous catalyst. ${ }^{16}$ It was successfully used for the synthesis of hydroxyphthalans 8 under both conventional heating and microwave irradiation (Scheme 4).

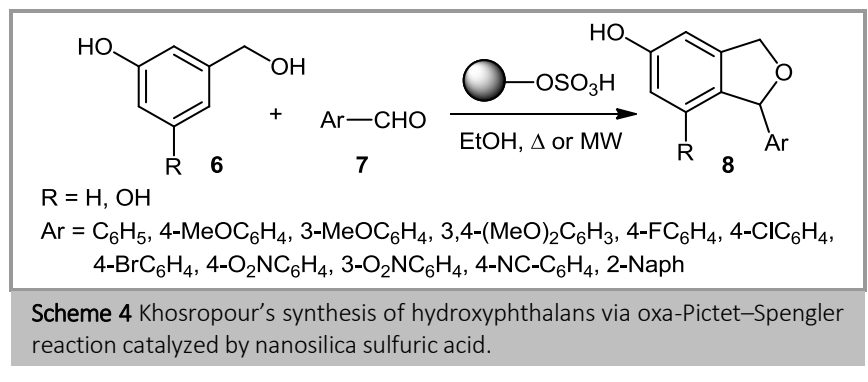

\subsection{Garratt-Braverman cyclization}

A valid synthetic approach to benzofused phthalans is the GarrattBraverman (GB) reaction, consisting in a base-promoted cyclization of bis(3-aryl-2-propargyl)ethers (Scheme 5). At first reported by Iwai and Ide, ${ }^{17}$ the mechanism was deeply investigated by Garratt et al., which hypothesized the formation of bis-allene 10, followed by rearrangement to the product $\mathbf{1 2}$ passing through the diradical intermediate $\mathbf{1 1}$ (Scheme 5). ${ }^{18}$

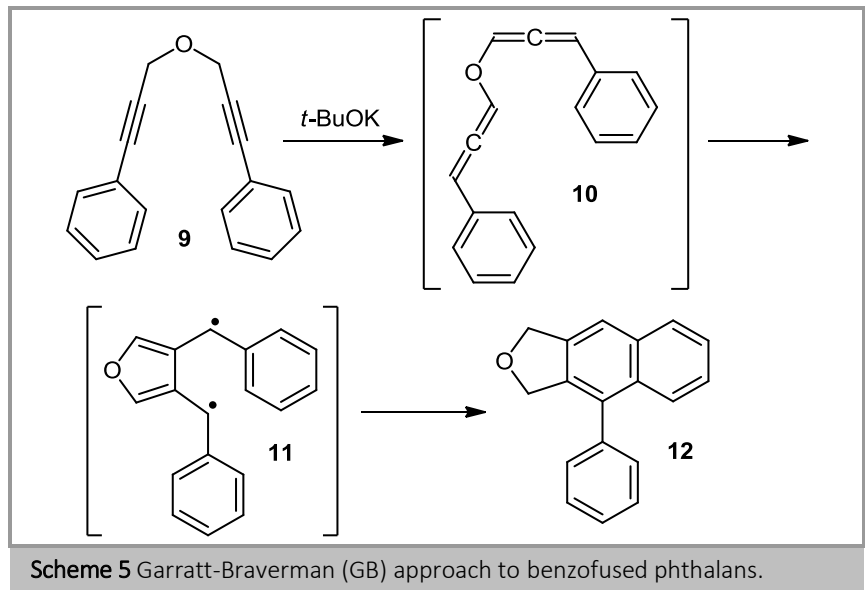

A wide study on GB route to substituted benzofused phthalans was carried out by Basak's group: in particular, for unsymmetrical bispropargyl ethers they found a good selectivity in the cyclization 
step only using aryl rings of different electronic properties, i.e. one donating and the other withdrawing (Scheme 6). ${ }^{19}$

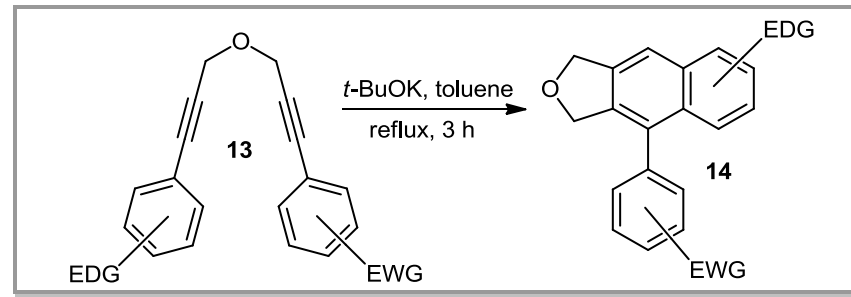

Scheme 6 Selective Garratt-Braverman (GB) cyclization of unsymmetrical bispropargyl ethers.

\subsection{Diels-Alder and related reactions}

Intramolecular Diels-Alder (IMDA) is a convenient methodology for the synthesis of many polycyclic organic compounds, including phthalans. A very common approach is the $[4+2]$ cycloaddition of 2,4-dien-1-yl propargyl ethers 15 or their analogues under thermal or metal-catalyzed conditions, which provides phthalans $\mathbf{1 7}$ as final products after an aromatization step of resulting dihydrophthalan cycloadducts 16 (Scheme 7).

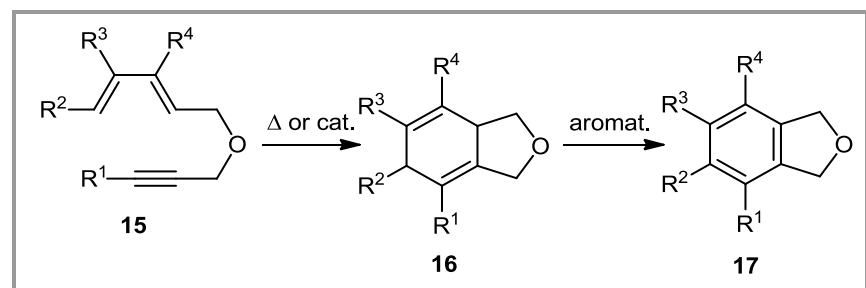

Scheme 7 Intramolecular Diels-Alder (IMDA) of 2,4-dien-1-yl propargyl ethers under thermal or metal-catalyzed conditions.

Several examples of thermal intramolecular Diels-Alder of these systems are described in the literature. Shealy et al. reported the reaction of retinyl 2-propynyl and 2-butynyl ethers, performed in refluxing ethanol and toluene respectively; cycloadducts were treated at room temperature with 2,3-dichloro-5,6-dicyano-1,4benzoquinone (DDQ) in dry benzene yielding the corresponding phthalans. ${ }^{20}$ Moreover, Fernandez de la Pradilla and coll. examined the IMDA of 2-sulfinyl butadienes tethered to unactivated alkynes, including propargyl ether groups. ${ }^{21}$ Thermal IMDA on slightly different compounds was studied by Kanematsu et al.: they investigated the preparation of pyrrole- or furan-fused phthalans 20 through Diels-Alder reaction of propargyl ethers 18, performed in toluene at $150^{\circ} \mathrm{C}$ in sealed tubes for $12 \mathrm{~h}$, followed by aromatization of dihydrophthalans 19 with DDQ in benzene or with Pd/C in AcOEt at room temperature (Scheme 8).22

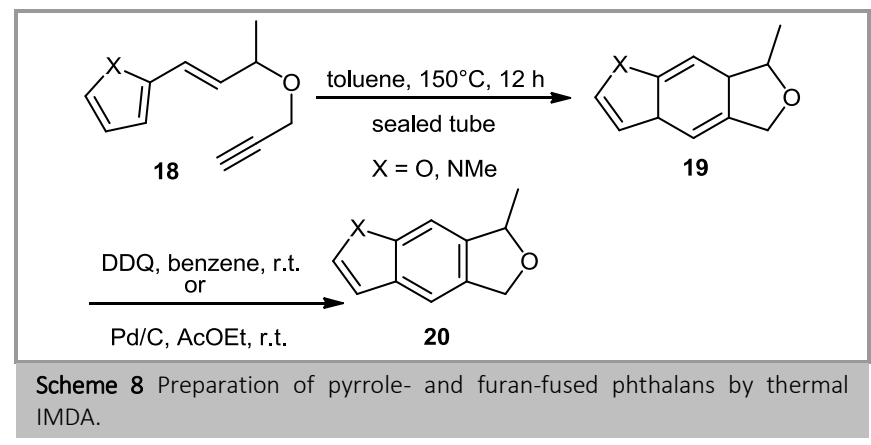

Recently, many protocols for metal-catalyzed IMDA of 2,4-dien-1-yl propargyl (and similar) ethers were also developed. The proposed mechanisms for these formal [ $4+2]$ cycloadditions are generally multi-step with a central role of metal species, including oxidative addition-reductive elimination sequence and/or ionic intermediate formation.

Dudley et al. reported a breakthrough methodology for Rhpromoted Diels-Alder-type reaction of tethered alkyne-dienoate substrates, including ether 21: the reaction was performed at room temperature using a cationic rhodium(I) norbornadiene catalyst (10 mol\%) together with silver hexafluoroantimonate (20 mol\%) as additive, followed by treatment with DDQ.23 The authors hypothesized an initial coordination of $\mathrm{Rh}(\mathrm{I})$ to the $\pi$-system, followed by cyclization to rhodium(III) intermediate $\mathbf{2 2}$ and reductive elimination to regenerate $\mathrm{Rh}(\mathrm{I})$ and release 23 , which is later oxidized to corresponding phthalan 24 (Scheme 9).

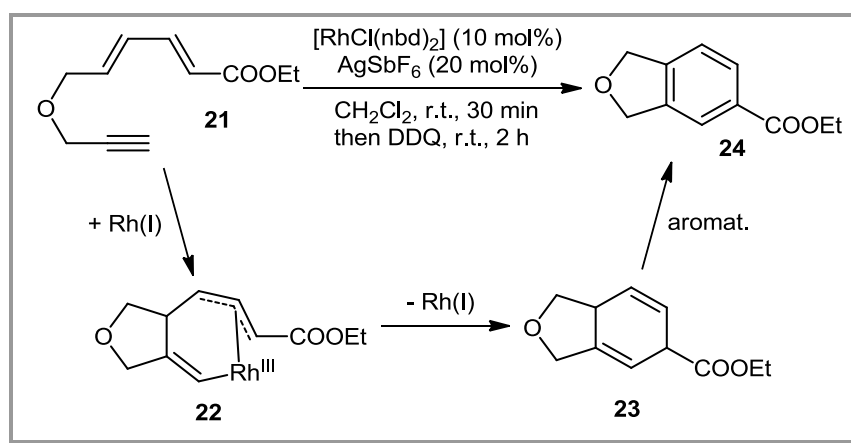

Scheme 9 Rh-promoted formal IMDA of tethered alkyne-dienoate substrates

Liang and coll. described instead a Pt-catalyzed cycloaddition of 4acetoxy-2-en-5-yn-1-yl propargyl ethers 25. ${ }^{24}$ Under Pt catalysis, the propargylic acetate group underwent a 1,3-acyloxy migration affording the corresponding allene intermediate $\mathbf{2 6}$, followed by IMDA-type and aromatization reactions to give $\mathbf{3 0}$. The proposed mechanism for formal cycloaddition proceeded with the formation of metal carbene complex 27, which through ionic intermediate $\mathbf{2 8}$ gave phthalan $\mathbf{2 9}$ (Scheme 10).

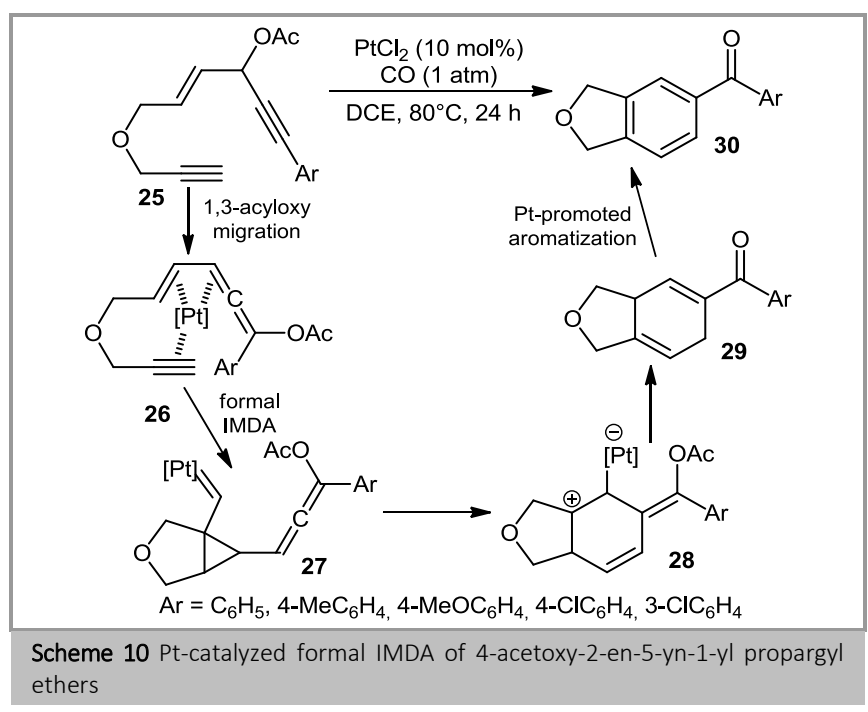

Moreover, Zhang developed a facile synthesis of polysubstituted phthalans by means of a Pd-catalyzed tandem process, ${ }^{25}$ consisting of: a) addition of terminal alkyne groups of dipropargyl ethers $\mathbf{3 1}$ 
to electron-poor alkynes 32 affording the 4-en-2-yn-1-yl propargyl ethers 33; b) propargyl-allenyl isomerization to the corresponding allene derivative 34 ; c) palladium-mediated formal IMDA, followed by aromatization process of cycloadducts $\mathbf{3 5}$ to give final products 36 (Scheme 11).

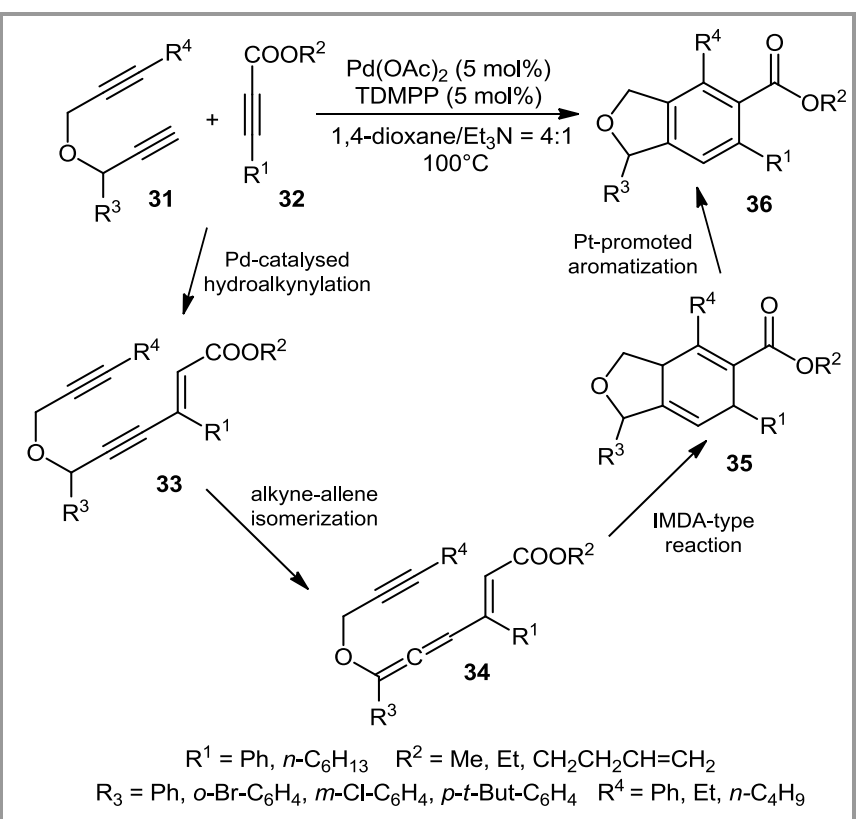

Scheme $11 \mathrm{Pd}$-catalyzed tandem hydroalkynylation, isomerization, Diels-Alder cycloaddition and aromatization developed by Zhang's group.

The IMDA route to phthalans is also possible, both under thermic and metal-catalyzed conditions, with a different class of molecules: 2-propargyloxymethyl and 2-allyloxymethyl furans (Scheme 12).

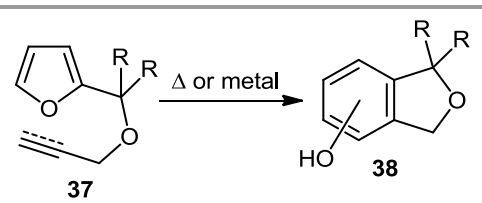

Scheme 12 Synthetic approach to phthalans by IMDA of 2-propargyloxymethyl and 2-allyloxymethyl furans under thermal or metal-catalyzed conditions.

This alternative approach was first developed by Wu et al., which described the thermal cyclization of 5-sulfur-substituted furans $\mathbf{3 9}$, performed at $85^{\circ} \mathrm{C}$ with catalytic amounts of $t$-BuOK in $t$-BuOH. ${ }^{26}$ Surprisingly, this protocol produced 3-thio-substituted phthalans 43 if furans 39 are functionalised with a thioether group, while with a sulfoxide or sulfone group they gave 6-thio-substituted phthalans 44. A possible mechanism is that [4+2] cycloaddition took place on the furfuryl allenyl ethers $\mathbf{4 0}$ affording the bridged cycloadduct 41, followed by its cleavage to give the zwitterionic intermediate 42; in the case of alkylthio group, an uncommon 1,4-rearrangement took place to yield $\mathbf{4 3}$, whereas an analogous 1,2-shift generated phthalans $\mathbf{4 4}$ for alkyl-sulfoxide or -sulfone groups (Scheme 13). The same approach was further investigated by Torosyan ${ }^{27}$ and, more recently, extended to 2-allyloxymethyl furans by Demircan's group. ${ }^{28}$

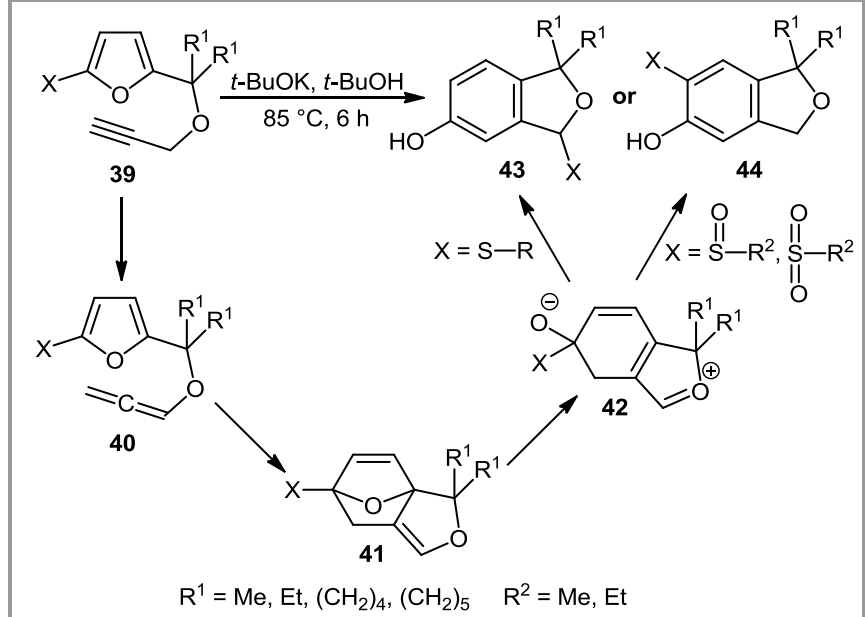

Scheme 13 Thermal IMDA of 5-sulfur-substituted furans.

Echavarren and coll. developed a platinum-catalyzed protocol for formal IMDA of furfuryl propargyl ethers: in refluxing acetone with $\mathrm{PtCl}_{2}$ or $\left[\mathrm{PtCl}_{2}\left(\mathrm{MeCN}_{2}\right]\right.$ as catalyst $(5 \mathrm{~mol} \%)$ for $16 \mathrm{~h}$, formal cycloaddition of furan $\mathbf{4 5 a}$ gave an equimolar mixture of 5hydroxyphthalan 46a and 4-hydroxyphthalan 47a, while with 5methyl-substituted furan $\mathbf{4 5 b}$ only product $\mathbf{4 7} \mathrm{b}$ was obtained (Scheme 14).29 In particular, the reaction seems to proceed with the formation of a cyclopropyl platinum(II) carbene intermediate. A similar mechanism (i.e. via metal carbenoid rearrangement) was also hypothesized by Hashmi et al. for the synthesis of several 1,3dihydroisobenzofurans by Au-promoted formal Diels-Alder of many poly-substituted 2-propargyloxymethyl furans. ${ }^{30}$

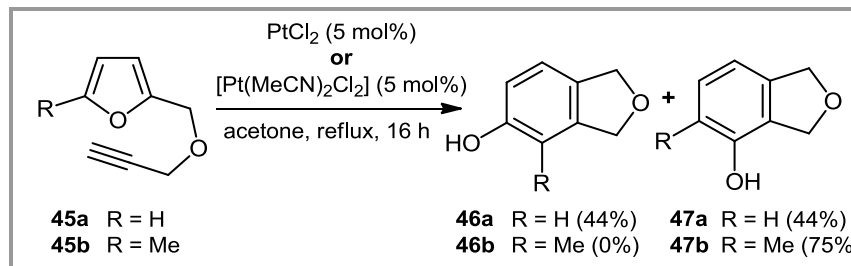

Scheme 14 Hydroxyphthalans synthesis by Platinum(II)-catalyzed formal IMDA of 2-propargyloxymethyl furans.

In addition to the above discussed IMDA protocols, a more recent synthetic approach to phthalans based on [4+2] cycloadditions is the hexadehydro Diels-Alder (HDDA) of triynes 48. The reaction generally proceeds with the formation (under thermal or metalmediated conditions) of benzyne intermediate 49, which then undergoes a nucleophilic addition step to give functionalised phthalans $\mathbf{5 0}$ (Scheme 15).

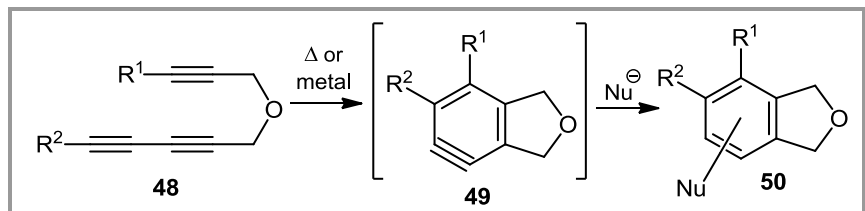

Scheme 15 Synthetic approach to functionalised phthalans by hexadehydro Diels-Alder (HDDA) reaction of triynes.

For this purpose, a very large number of nucleophiles were deeply investigated: $\mathrm{AgBF}_{4}, \mathrm{AgCF}_{3}$ and $\mathrm{AgSCF}_{3}$ were used for the synthesis of fluorinated, trifluoromethylated and trifluoromethylthiolated phthalans, respectively; ${ }^{31}$ silver trifluoroacetate found application 
in the preparation of poly-substituted hydroxyphthalans, obtained from the corresponding trifluoroacetoxy derivatives after a simple chromatographic purification step; ${ }^{32} \mathrm{Li}_{2} \mathrm{CuCl}_{4}$ was very efficient for dichlorination of HDDA-generated benzynes, giving 4,5-dichloro1,3-dihydroisobenzofurans in good yields; 33 halo-hydrocarbons such as $\mathrm{CH}_{2} \mathrm{Cl}_{2}, \mathrm{CHCl}_{3}, \mathrm{CH}_{2} \mathrm{Br}_{2}$ and $\mathrm{CH}_{2} \mathrm{I}_{2}$ were used to convert many bis-2,4-diynyl ethers into chloro- bromo- and iodo-functionalized phthalans, in the presence of a ruthenium alkylidene complex as catalyst; ${ }^{34}$ various phenols, instead, gave at the ortho-position a phenol-ene process with HDDA-generated benzynes, generating aryl-substituted phthalans; ${ }^{35}$ linear and cyclic alkyl sulfides were applied for obtaining - through $S$-aryl sulfur ylide intermediates many 5-alkylthio-substituted phthalans; ${ }^{36} \mathrm{~N}$-heterocyclic carbene (NHC) boranes were used in the selective hydroboration of HDDAgenerated benzynes (i.e. without reacting with triyne precursor), so providing borane-functionalized phthalans; ${ }^{37}$ very recently, also several nitriles were found able to react, in the presence of $\mathrm{AgSbF}_{6}$ as catalyst, with benzyne intermediates, inducing a Ritter-type step to give amide- or imide-substituted 1,3-dihydroisobenzofurans. ${ }^{38}$

\section{$2.4[2+2+2]$ Cyclotrimerization of alkynes}

Metal-catalyzed [2+2+2] cyclotrimerization of alkynes is a powerful methodology for the preparation of several benzofused moieties, including phthalans. In fact, the reaction of dipropargyl ethers $\mathbf{5 1}$ with functionalised alkynes $\mathbf{5 2}$ in the presence of a transition metal catalyst provides poly-substituted phthalans $\mathbf{5 3}$ (Scheme 16).

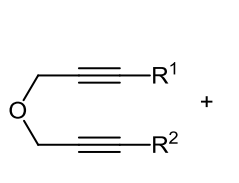

51

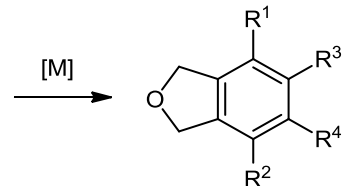

53
Scheme 16 Synthesis of phthalans by metal-catalyzed $[2+2+2]$ cyclotrimerization of alkynes.

The first example of $[2+2+2]$ cycloaddition approach to phthalans was developed by Grigg's group, which described the reaction of diynes, including bis-propargyl ether 54, with monoacetylenes $\mathbf{5 5}$ promoted by Wilkinson's catalyst $\mathrm{RhCl}\left(\mathrm{PPh}_{3}\right)_{3}$ (0.5-2 mol\%) under mild conditions (Scheme 17). ${ }^{39}$

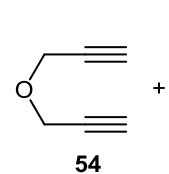

54

$$
\left.\right|_{55} ^{R}
$$

$\mathrm{RhCl}\left(\mathrm{PPh}_{3}\right)_{3}(0.5-2 \mathrm{~mol} \%)$

$\mathrm{EtOH} / \mathrm{CHCl}_{3}=(2: 3 \mathrm{v} / \mathrm{v})$

$0-80{ }^{\circ} \mathrm{C}, 10 \mathrm{~min}-3 \mathrm{~h}$

$\mathrm{R}=\mathrm{H}, n-\mathrm{C}_{3} \mathrm{H}_{7}, \mathrm{CH}_{2} \mathrm{OH}, \mathrm{Ph}, \mathrm{SiMe}_{3}$

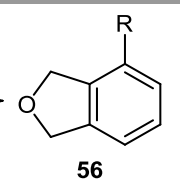

56
Scheme 17 First example of Rh-catalyzed $[2+2+2]$ cycloaddition approach to phthalans.

In few years, Rh-promoted [2+2+2] cyclotrimerization of alkynes became one of the most common synthetic routes to functionalised 1,3-dihydroisobenzofurans. A wide range of substrates have been investigated, including diynes and alkynes with high degree of steric hindrance, ${ }^{40}$ perfluoroalkylacetylenes, ${ }^{41}$ glycoside units bearing bis-propargyl ethers, ${ }^{42}$ 1-alkynylphosphine sulphides, ${ }^{43}$ propargyl glycine aminoacids, ${ }^{44}$ as well as synthetic equivalents of alkynes like enol ethers/acetates ${ }^{45}$ or (Z)-(2-bromovinyl)trifluoroborate, ${ }^{46}$ and even solid-supported diynes. ${ }^{47}$ In addition, several rhodium(I) complexes were found to be very efficient as catalysts, obtained by treatment of a rhodium(I) precursor with proper ligands: 4,5-bis(2oxazolinyl)xanthene (Xabox), ${ }^{48} \mathrm{~N}$-phosphino $t$-butylsulfinamides (PNSO), ${ }^{49}$ tris (meta-sulfonatophenyl)phosphine trisodium salt (tppts) ${ }^{50}$ and a $2,2^{\prime}$-bipyridine cationic derivative ${ }^{51}$ (both watersoluble), and more recently also $\mathrm{N}$-heterocyclic carbenes supported on silica. ${ }^{52}$

A very exciting application of Rh-catalyzed $[2+2+2]$ cycloadditions is the enantioselective synthesis of axially chiral compounds bearing phthalan moieties, performed in the presence of enantiopure chiral ligands. The first example was reported in 2006 by Tanaka and coll., in which developed a protocol for enantioselective intermolecular $[2+2+2]$ cycloaddition of diynes $\mathbf{5 7}$ with trimethylsilylynamides $\mathbf{5 8}$ for the preparation with high enantioselectivity (up to 98\% ee) of axially chiral anilides $\mathbf{5 9}$, using $\left[\mathrm{Rh}(\operatorname{cod})_{2}\right] \mathrm{BF}_{4}$ and $(S)$-xyl-BINAP $(10$ mol\%) as catalytic system, in $\mathrm{CH}_{2} \mathrm{Cl}_{2}$ at room temperature (Scheme 18). ${ }^{53}$

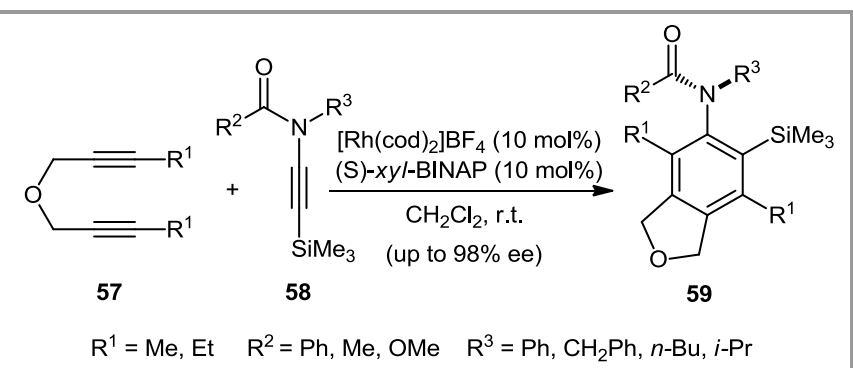

Scheme 18 Tanaka's synthesis of axially chiral anilides via enantioselective Rhcatalyzed $[2+2+2]$ cycloaddition of alkynes.

The same group then developed a enantioselective synthesis of the $C_{2}$ symmetric tetra-ortho-substituted axially chiral biaryls $\mathbf{6 2}$, performed with $\left[\mathrm{Rh}(\mathrm{cod})_{2}\right] \mathrm{BF}_{4}(5 \mathrm{~mol} \%)$ as metal precursor and (S)-Segphos (5 mol\%) as chiral ligand (Scheme 19). ${ }^{54}$ Similar protocols have been described in the following years, concerning the synthesis of many chiral compounds bearing phthalan moieties: biaryl diphosphines, ${ }^{55}$ diphosphonates and dicarboxylates, ${ }^{56} \mathrm{~N}, \mathrm{O}$ biaryls, ${ }^{57} P$-stereogenic alkynylphosphine oxides, ${ }^{58}$ as well as axially chiral $N, N$-dialkylbenzamides, ${ }^{59} 1$-arylisoquinolines ${ }^{60}$ and hydroxy carboxylic acid derivatives. ${ }^{61}$

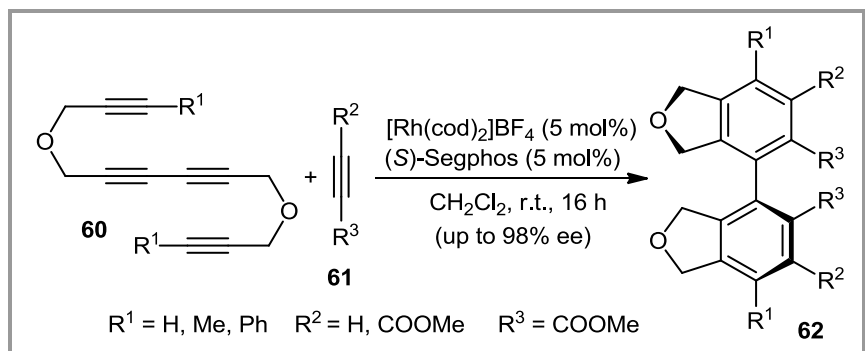

Scheme 19 Synthesis of tetra-ortho-substituted axially chiral biaryls via enantioselective Rh-catalyzed [2+2+2] cycloaddition of alkynes.

Although rhodium-based complexes are the most applied catalysts for phthalans synthesis via $[2+2+2]$ cyclotrimerization of alkynes, other transition metals were also intensively studied.

In 2002, Sugihara et al. reported the first synthetic route to 1,3dihydroisobenzofurans by Co-catalyzed $[2+2+2]$ cyclotrimerization reactions, performed with methylidynetricobalt nonacarbonyl $(2$ mol\%) in refluxing toluene. ${ }^{62}$ Many cobalt-based catalytic systems 
were then explored, ranging from the most common $\left[\mathrm{Co}_{2}(\mathrm{CO})_{8}\right]^{63}$ and $\left[\mathrm{CpCo}(\mathrm{CO})_{2}\right]^{64}$ to phosphine complexes like $\left[\mathrm{CoBr}\left(\mathrm{PPh}_{3}\right)_{3}\right], 65$ $\left[\mathrm{CoI}_{2}\left(\mathrm{PPh}_{3}\right)_{2}\right]^{66}$ and $\left[\mathrm{CoCl}\left(\mathrm{PPh}_{3}\right)_{3}\right]{ }^{67}$ Hapke and coll. described a systematic study by ligand variation on the $\left[\mathrm{CpCo}^{\mathrm{I}}(\right.$ bisphosphite $\left.)\right]$ and $\left[\mathrm{CpCo}^{\mathrm{I}}\right.$ (olefin)(phosphite)] complexes reactivity in the $[2+2+2]$ cycloaddition route to phthalans, ${ }^{68}$ while Gandon et al. developed a set of air-stable cobalt cyclopentadienyl complexes incorporating a fumarate and a CO ligands. ${ }^{69}$ Okamoto's group studied intensively a catalytic system for $[2+2+2]$ cyclotrymerization of alkynes based on $\mathrm{CoCl}_{2} \cdot 6 \mathrm{H}_{2} \mathrm{O} / \mathrm{Zn}$ in the presence of 2-(arylimino)methylpyridine (dipimp) as ligand: in particular, they found that the addition of a silver(I) salt $\left(\mathrm{AgOTf}_{\text {or }} \mathrm{AgSbF}_{6}\right)^{70}$ or the dimethyl phthalate ${ }^{71}$ as additive significantly increased its catalytic activity (Scheme 20).

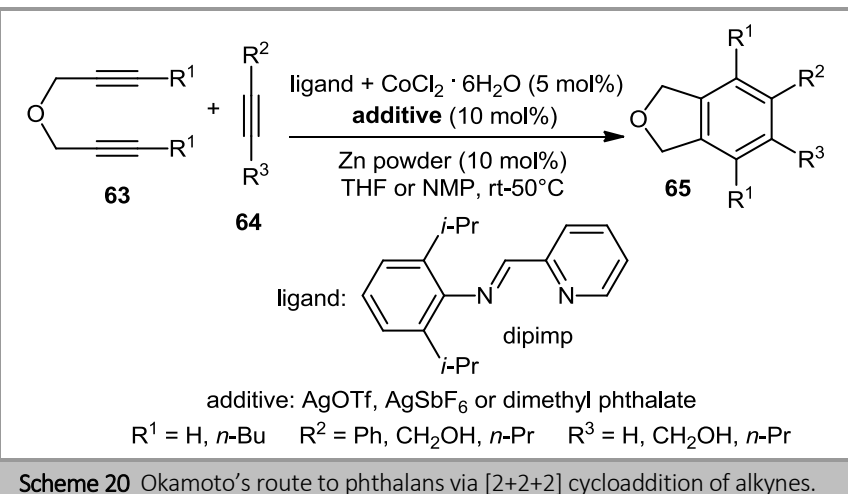

Very recently, few examples of asymmetric Co(I)-catalyzed [2+2+2] cyclotrimerization of alkynes to axially chiral compounds bearing dihydrofuran-fused phthalans have been reported.72

Phthalans preparation by Ru-promoted $[2+2+2]$ cyclotrimerization has long been investigated by Yamamoto and coll., always exploiting $\mathrm{Cp} * \mathrm{Ru}(\operatorname{cod}) \mathrm{Cl}$ complex (with $\mathrm{Cp}^{*}=$ pentamethylcyclopentadienyl) as catalytic system. In 2000, the cycloaddition of unsymmetrical 1,6diynes, including ether $\mathbf{6 6}$, with mono-substituted alkynes like 1hexyne $\mathbf{6 7}$ was reported: the reaction, performed with low catalyst loading (1 mol\%) at room temperature and in 1,2-dichloroethane as solvent, gave the corresponding cycloadduct $\mathbf{6 8}$ in good yields (75\%) and high meta-regioselectivity (Scheme 21). ${ }^{73}$ The authors then extended the same protocol to intramolecular [2+2+2] alkyne cycloadditions ${ }^{74}$ and to more functionalized substrates, such as bispropargyl ethers bearing ribosyl units, ${ }^{75}$ diynes or alkynes with boronate groups ${ }^{76}$ and iododiynes. ${ }^{77}$ However, more recently the synthesis of phthalan-based compounds has been extended to other ruthenium-based catalysts. ${ }^{78}$

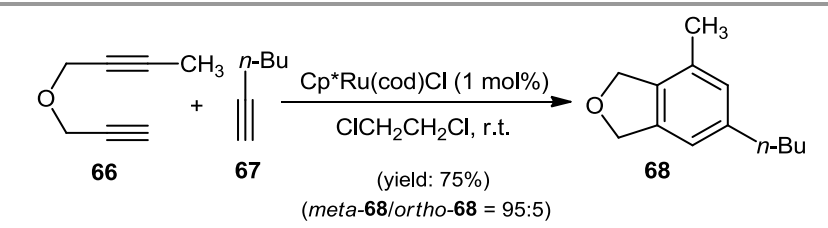

Scheme 21 First example of phthalans synthesis by Ruthenium-catalyzed [2+2+2] cyclotrimerization of alkynes.

Iridium compounds have also been studied as catalysts for $[2+2+2]$ cycloadditions of $\alpha, \omega$-diynes with monoalkynes to give benzofused derivatives, including phthalans. Takeuchi and coll. have found that $[\operatorname{Ir}(\operatorname{cod}) \mathrm{Cl}]_{2}$ combined with the 1,2-bis(diphenylphosphino)ethane (dppe) ligand was an efficient catalyst for these reactions, ${ }^{79}$ while
Michelet and Ratovelomanana-Vidal proposed the use of complex $\left[\{\operatorname{Ir}(\mathrm{H})[\mathrm{rac} \text {-binap }]\}_{2}(\mu-\mathrm{I})_{3}\right] \mathrm{I}$, able to tolerate a broad range of groups (alcohol, alkyl, ether and halogen) on the alkynyl substrate. ${ }^{80}$ More recently, a $\mathrm{SnCl}_{2}$-induced cyclotrimerization of alkynes catalyzed by phosphine-free $[\mathrm{Ir}(\mathrm{cod}) \mathrm{Cl}]_{2}$ was developed. ${ }^{81}$ Moreover, a couple of protocol for the synthesis of phthalan-based axially chiral systems through enantioselective Ir-catalyzed [2+2+2] cyclotrimerization of alkynes were investigated by Shibata's group. ${ }^{82}$ Few examples for phthalans synthesis via [2+2+2] cycloaddition of alkynes catalyzed by other transition metals like nickel, ${ }^{83}$ iron, ${ }^{84}$ palladium $^{85}$ and titanium ${ }^{86}$ were also reported.

\subsection{Cycloetherification of ortho-substituted aromatics}

The most common synthetic approach to phthalans is based on the cycloetherification of benzyl alcohols (or also their derivatives, such as benzaldehydes and benzyl alkoxides generated in situ) having an appropriate ortho-substituent. Although several ortho-groups have been deeply investigated including epoxides, 87 oxetanes, ${ }^{88} 1,2,3-$ triazole rings, ${ }^{89}$ quaternary ammonium salts, ${ }^{90}$ benzyl halides or alcohols ${ }^{91}$ and alkenes, ${ }^{92}$ particularly interesting is the 5-exo-dig cyclization of ortho-alkynyl $O$-benzyl-functionalized aromatics 69 to give 1-alkylidene-1,3-dihydroisobenzofurans 70 (Scheme 22), not obtainable with all the above-described methodologies. However, the reaction is generally promoted by a stoichiometric amount of base or catalytic amounts of a metal catalyst.

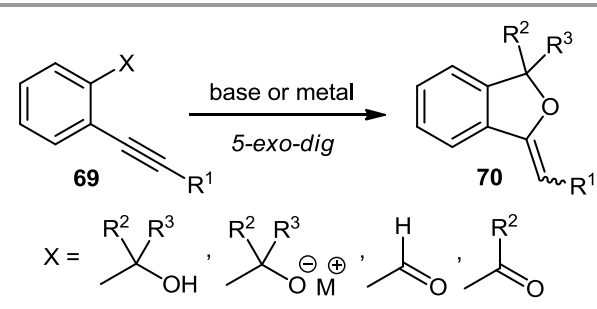

Scheme 22 Synthesis of alkylidenephthalans by 5-exo-dig cycloetherification of benzyl alcohols (or their derivatives) bearing an ortho-alkynyl group.

Padwa et al. reported 5-exo-dig cyclization of 2-(arylethynyl)benzyl alcohols with two different basic conditions (i.e. $\mathrm{KOH}$ in refluxing $\mathrm{MeOH}$ or $\mathrm{NaH}$ in refluxing THF), ${ }^{93}$ while Liu's group proposed a $t$ BuOK-promoted protocol for the cycloetherification of very similar substrates. ${ }^{94}$ Larock and coll. described the iodocyclization of 2-(1alkynyl)benzylic alcohols, performed with $\mathrm{I}_{2}$ and $\mathrm{NaHCO}_{3}$ as base: although 6-endo-dig cyclization is generally preferred, with tertiary alcohols only (Z)-alkylidenephthalans were obtained, by exploiting the gem-dialkyl effect. ${ }^{95}$ Hiroya and Sakamoto described a TBAFpromoted cyclization of 2-ethynylbenzyl alcohols $\mathbf{7 1}$ (Scheme 23): working in refluxing THF, alkylidenephthalans $\mathbf{7 2}$ were obtained with good yields in few hours; only with steric-hindered substrates small amounts of the corresponding 6-endo-dig cycloadducts were also obtained. ${ }^{96}$

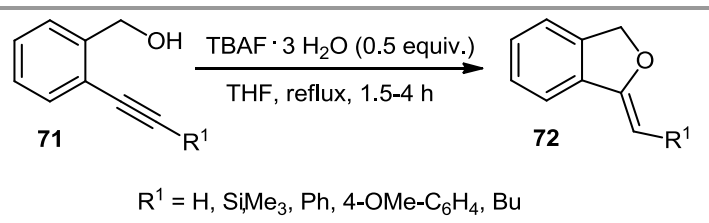

Scheme 23 Synthesis of alkylidenephthalans by TBAF-promoted 5-exo-dig cycloetherification of 2-ethynylbenzyl alcohols. 
Herndon proposed instead a potassium fluoride-mediated cyclization of $O$-silylated benzyl alcohols with a carbonylsubstituted alkyne group in the ortho-position. ${ }^{97}$ As an alternative, ortho-alkynylbenzaldehydes have been studied as substrates for 1,3-dihydroisobenzofurans preparation by base-promoted 5-exodig cycloetherifications. ${ }^{98}$ However, metal-catalyzed 5-exo-dig cyclization of $o$-alkynyl benzyl alcohols (or derivatives) represents a more common methodology: alkaline earth,99 lanthanides, ${ }^{100}$ actinides $^{101}$ and transition metals (such as mercury, ${ }^{102}$ zinc, ${ }^{103}$ gold, ${ }^{104}$ platinum ${ }^{105}$ and rhodium ${ }^{106}$ ) compounds, in fact, have been widely investigated as catalysts for phthalan synthesis via cycloetherification. Nevertheless, the most investigated systems are based on copper or palladium.

In 2010, Lee et al. developed the first protocol for $\mathrm{Cu}(\mathrm{I})$-catalyzed preparation of alkylidenephthalans through 5-exo-dig cyclization: treatment of 2-iodobenzyl alcohols $\mathbf{7 3}$ with phenylacetylene $\mathbf{7 4}$, using $\mathrm{Cu}_{2} \mathrm{O}$ and 4,5-bis(diphenylphosphino)-9,9-dimethylxanthene (xantphos), gave (Z)-alkylidenephthalans $\mathbf{7 5}$ in good yields (Scheme 24).107

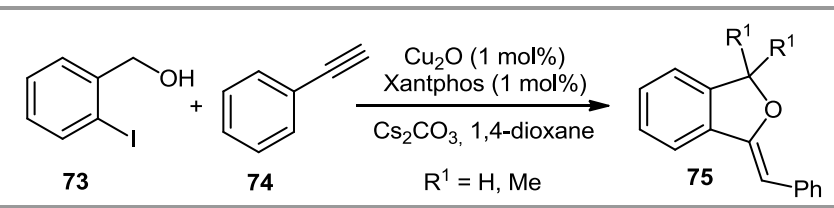

Scheme 24 Lee's synthetic route to phthalans, performed with $\mathrm{Cu}_{2} \mathrm{O}$ and xantphos as catalytic system.

In the same year, Perumal's group described a $\mathrm{Cu}(\mathrm{OTf})_{2}$-promoted synthesis of alkylidenephthalans, ${ }^{108}$ while more recently Brent Gunnoe and coll. investigated the use of copper(I) complexes bearing $\mathrm{N}$-heterocyclic carbene (NHC) ligands for intramolecular hydroalkoxylation of alkynols. ${ }^{109}$

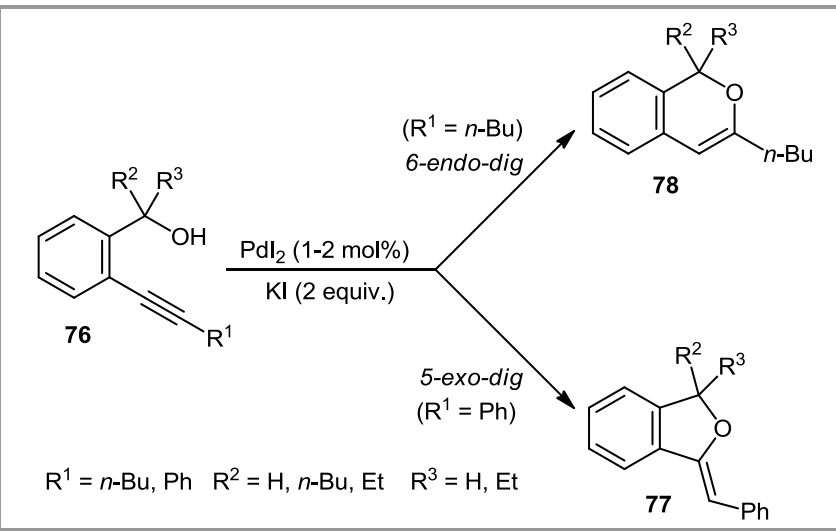

Scheme 25 Gabriele's protocol for Pd-catalyzed cyclization of 2-alkynylbenzyl alcohols into (Z)-alkylidenephthalans and $1 \mathrm{H}$-isochromenes.

Palladium-catalyzed 5-exo-dig cyclization of ortho-alkynyl $O$-benzylfunctionalized aromatics have been intensely studied by Gabriele and coworkers. In 2003, they reported the cycloisomerization of 2alkynylbenzyl alcohols 76 into (Z)-alkylidenephthalans 77 and $1 H$ isochromenes 78 using $\mathrm{PdI}_{2}$ (1-2 mol\%) in the presence of $\mathrm{KI}$ as additive:110 in particular, benzyl alcohols with alkyl-substituted triple bond gave preferentially 6-endo-dig reaction, while substrates with an aryl-substituted triple bond afforded phthalans as main product (Scheme 25). In 2004 they extended this $\mathrm{PdI}_{2} / \mathrm{KI}$ system to the oxidative carbonylation of $o$-alkynyl-substituted benzaldehydes and phenyl ketones 79 to give 1-(alkoxycarbonyl)methylenephthalans $\mathbf{8 0}$ in good yields (Scheme 26). ${ }^{111}$

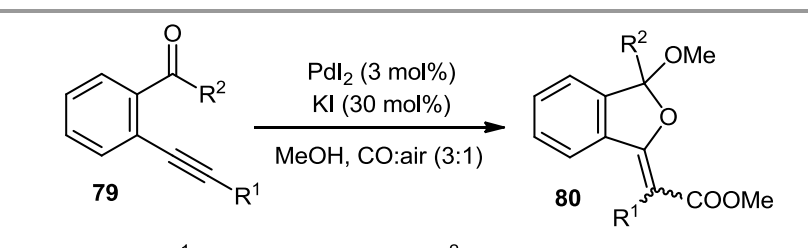

$\mathrm{R}^{1}=\mathrm{H}, n-\mathrm{Bu}, \mathrm{Ph}, \mathrm{TMS} \quad \mathrm{R}^{2}=\mathrm{H}, \mathrm{Me}, \mathrm{Ph}$

Scheme 26 Synthesis of 1-(alkoxycarbonyl)methylene-phthalans via oxidative carbonylation of ortho-alkynyl-substituted benzaldehydes and phenyl ketones.

More recently, they developed a similar protocol for (Z)alkylidenephthalans synthesis from ortho-alkynyl aryloxiranes $\mathbf{8 1}$ through nucleophilic ring opening-heterocyclization-oxidative carbonylation process (Scheme 27). ${ }^{112}$

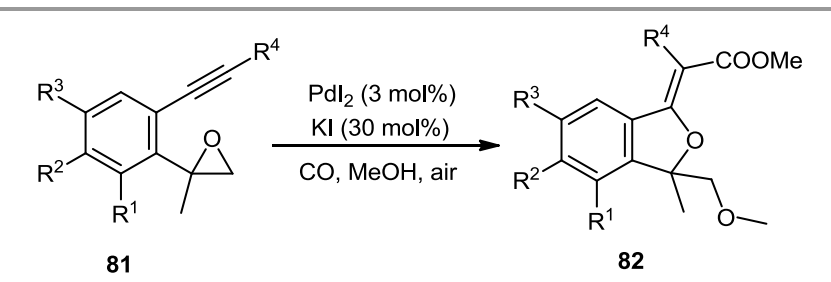

$\mathrm{R}^{1}=\mathrm{H}, \mathrm{F} \quad \mathrm{R}^{2}=\mathrm{H}$, OMe, F $\mathrm{R}^{3}=\mathrm{H}, \mathrm{Me}, \mathrm{OMe} \quad \mathrm{R}^{4}=\mathrm{H}, n-\mathrm{Bu}, \mathrm{Ph}, \mathrm{TMS}$ Scheme 27 Synthesis of (Z)-alkylidenephthalans from o-alkynyl aryloxiranes.

Although Kwon et al. developed a tandem Michael-Heck reaction of 2-iodobenzyl alcohols with electron-poor alkynes, ${ }^{113}$ most of the Pdpromoted routes to alkylidenephthalans involved a sequential Sonogashira coupling followed by 5-exo-dig cyclization. Abbiati et al. developed a microwawe-assisted protocol for the synthesis of (Z)-1alkylidene-3-methoxy-1,3-dihydroisobenzofurans 85 by reaction of functionalised 2-bromobenzaldehydes $\mathbf{8 3}$ and arylacetylenes $\mathbf{8 4}$ with $\mathrm{PdCl}_{2}\left(\mathrm{PPh}_{3}\right)_{2}$ as catalyst, $\mathrm{CuI}$ as additive, $t$-BuOK as base and $\mathrm{CH}_{3} \mathrm{OH}$ as reactant and solvent (Scheme 28). ${ }^{114}$ In 2006, Gundersen described one-pot Sonogashira coupling/5-exo-dig cyclization reaction between 2-ethynylbenzyl alcohol with 6-iodopurines, ${ }^{115}$ while a tandem Sonogashira/hydroalkoxylation protocol of functionalized 2-bromo- or 2-chlorobenzyl alcohols with several arylalkynes was reported by Buxaderas et al. in 2014.116

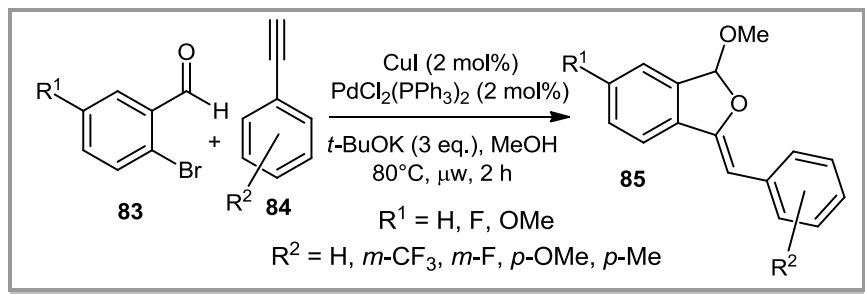

Scheme 28 Phthalans synthesis by Pd-promoted tandem Sonogashira coupling/5exo-dig cycloetherification.

Recently, palladium nanoparticles dispersed in glycerol phase were applied in the synthesis of many heterocycles, including phthalans by reaction of ortho-iodobenzyl alcohols with phenylacetylene. ${ }^{117}$

\subsection{Tandem carbonylative Sonogashira-cyclization reactions}

Recently Aronica et al.118 have described the synthesis of alkylidenephthalans via a palladium-catalyzed tandem 
carbonylative Sonogashira-cyclization reaction (Scheme 29). The cross coupling between ortho-ethynylbenzyl alcohols $\mathbf{8 6}$ and iodo arenes took place with complete conversion of the reagents and afforded the corresponding isobenzofurans $\mathbf{8 7}$ as a mixture of the two possible stereoisomers $\mathrm{E} / \mathrm{Z}, \mathrm{Z}$ being the major isomer. Notably, the relative amount of the stereoisomers changed after separation by column chromatography and the quantity of $\mathrm{Z}$ compound generally increased.

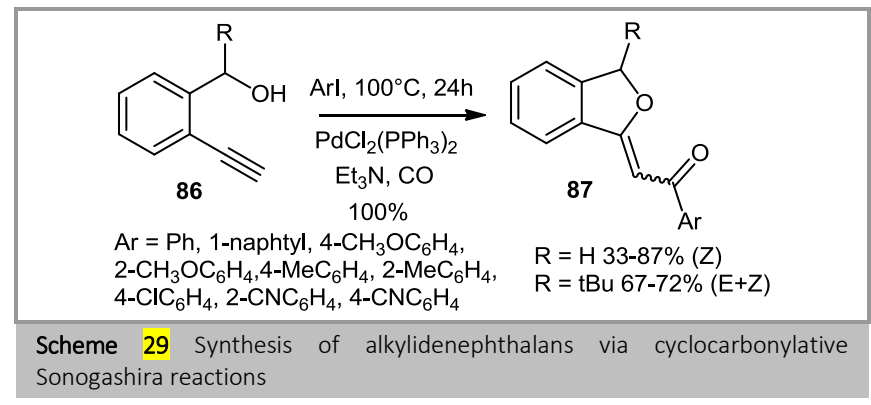

An experiment was performed in order to evaluate whether the observed interconversion of the two isomers was ascribable to the presence of acid during the purification step. The authors observed that a sample of pure E-isomer was converted into a $\mathrm{Z} / \mathrm{E}$ mixture (92/8) when it was treated with $\mathrm{SiO}_{2}$ in $\mathrm{CDCl}_{3}$. This result was explained with the mechanism depicted in Scheme 30.

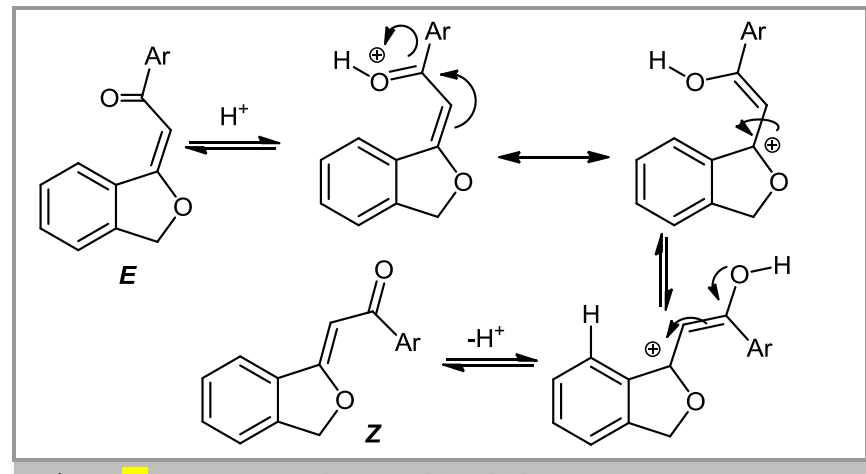

Scheme $\mathbf{3 0}$ Interconversion between $(E)$ and $(Z)$ stereoisomers.

The scope of the cyclization reaction was investigated by reacting aryl iodide bearing electron-donating $(\mathrm{Me}, \mathrm{OMe})$ or electronwithdrawing substituents $(\mathrm{Cl}, \mathrm{CN})$ in the ortho and para positions. In almost all cases alkylidenephthalans were obtained quantitatively except for the reactions performed with o- and pcianoaryl iodides, where significant amount of carbonylative Sonogashira by-products were also found. Finally, a curious behaviour for the reaction of 2-ethynylbenzyl alcohol 88 with 1iodo-4-nitrobenzene $\mathbf{8 9}$ was described by the authors: in addition to the expected phthalans 90, almost equal amounts of the corresponding amino derivative $\mathbf{9 1}$ were obtained. Its formation was explained with a reduction of $-\mathrm{NO}_{2}$ into $-\mathrm{NH}_{2}$ due to the presence of $\mathrm{Pd}$-hydride species in the reaction conditions (Scheme 31).

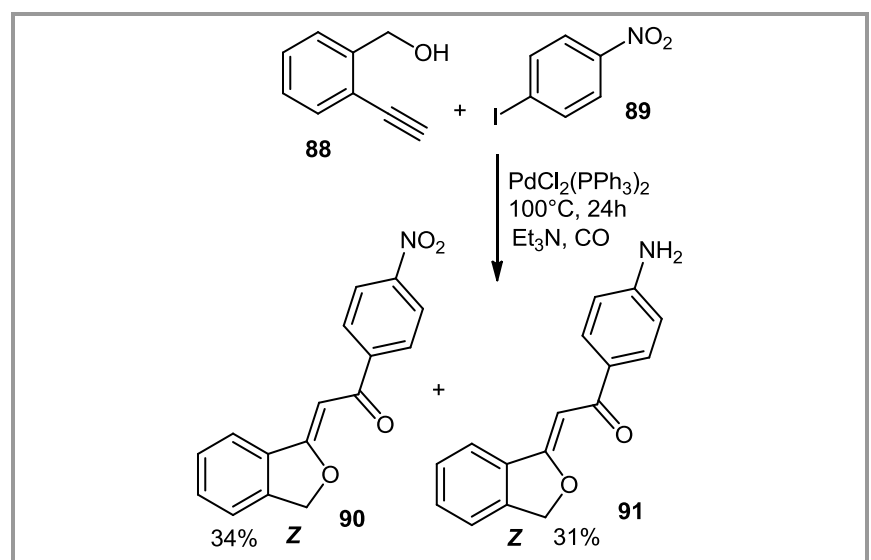

Scheme 31 Tandem carbonylative Sonogashira-cyclization reactions between (2-ethynylphenyl)methanol and 1-iodo-4-nitrobenzene.

\section{Isoindolines}

Several methods for the preparation of isoindolines scaffolds are reported in the literature. In particular many procedures based on cyclization strategies have been described. They can be divided into the following sections: a) amination of dihalides; b) intramolecular hydroamination; c) Diels-Alder and related reactions; d) $[2+2+2]$ cyclotrimerization of alkynes; e) cyclocarbonylative Sonogashira reaction.

\subsection{Amination of dihalides}

A traditional strategy for the construction of isoindoline motifs is based on the amination of suitable dihalides (Scheme 32).

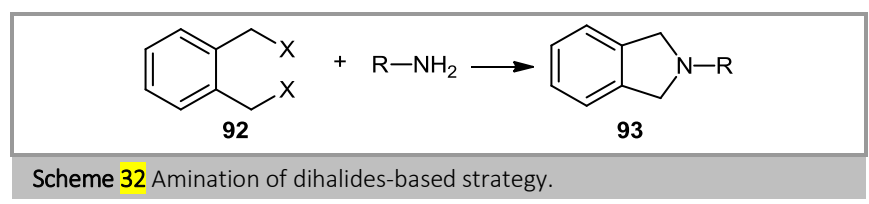

Indeed, one of the first example of isoindoline synthesis was reported in 1971 by Fraser and Renaud who generated the heterocyclic nucleus 95 through the reaction of methylamine with 1-(bromomethyl)-2-[bromo(phenyl)methyl]benzenes 94 (Scheme 33). ${ }^{119}$

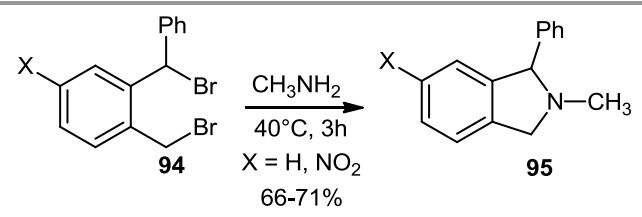

Scheme 33 First example of isoindolines synthesis via amination of dihalides

A few years later, the same method was employed by Cignarella and co-workers for the preparation of $\mathrm{N}-\mathrm{NH}$-functionalised isoindolines 97 (Scheme 34), useful precursors of indapamide, an effective diuretic agent used in the therapy of hypertension..$^{120}$ 


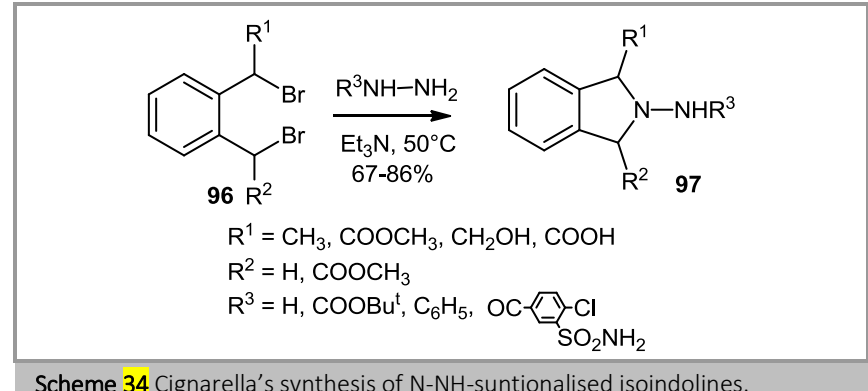

Scheme 34 Cignarella's synthesis of N-NH-suntionalised isoindolines.

More recently, Varma et al. developed a microwave-assisted heterocyclization approach which was applied to the synthesis of the isoindoline nucleus. ${ }^{121}$ The reaction of primary amines with $\alpha, \alpha$ bishalo-ortho-xylenes 98 in sealed vessel under aqueous MW irradiation turned out to be extremely useful for the synthesis of $\mathrm{N}$ substituted isoindolines $\mathbf{9 9}$ with good to excellent yields (Scheme 35). Moreover, the work-up of the reaction was greatly simplified because the products precipitated from the reaction medium at the end of the reaction and no column chromatography purification was necessary to isolate the products.

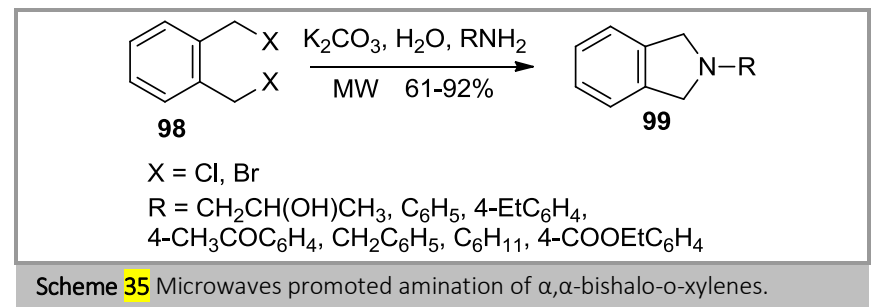

The work of Varma and Ju was then scaled up from $1 \mathrm{mmol}$ to 1 mole by Bernard and co-workers, who performed the reactions in a microwave apparatus with open vessels at atmospheric pressure. ${ }^{122}$ The reactions were completed after 30 minutes and the isoindolines derivatives were obtained with similar yields. Finally, in 2009, Subbarayappa et al. reported the synthesis of Nsubstituted isoindolines from $\alpha, \alpha$-dibromo-o-xylene and various primary amines in basic medium and at room temperature. ${ }^{123}$ In particular, the reactions performed using 1,4-dioxane as solvent and $\mathrm{NaOH}$ as base afforded the heterocycle derivatives 101-103 in excellent yields (Scheme 36). Anilines, benzyl and alkyl amines could be successfully used and the reaction can be applied to functionalised substrates containing both electron-donating and electron-withdrawing groups.

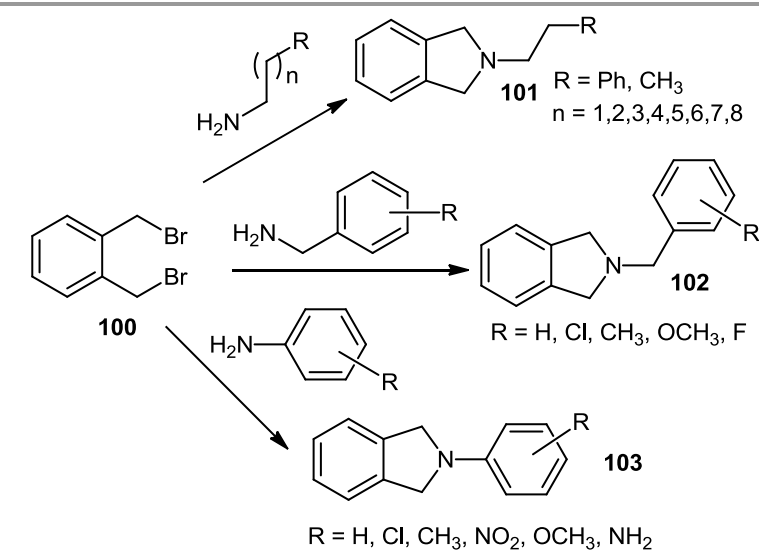

Scheme 36 Amination of $\alpha, \alpha$-dibromo-o-xylene with different primary amines.

\subsection{Intramolecular Hydroamination}

A convenient method for the synthesis of 1-substituted isoindolines is based on the hydroamination of 2-vinyl or 2-ethynyl benzilamines (Scheme 37), generally promoted by acid or basic reagents.<smiles>[R]NCc1ccccc1C#C</smiles>

104

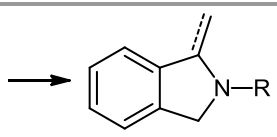

105
Scheme 37 General hydroamination method.

An acid-catalyzed intramolecular hydroamination approach to isoindolines was described by Henderson and co-workers in 2012.124 The reaction of 2-alkenylphenylsulphonamides with small amounts of triflic acid afforded the desired heterocycles with excellent yields (Scheme 38).

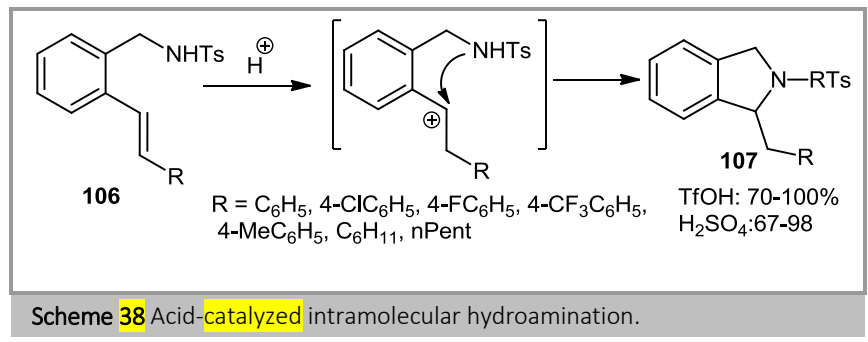

The reaction was supposed to take place through the formation of a benzylic cationic intermediate that was then trapped by the amine nitrogen. A drawback of this methodology was that it required triflic acid, a highly corrosive and expensive reagent. For these reasons the authors tested sulphuric acid and observed that all the precursors 106 underwent successful cyclization generating the isoindolines products $\mathbf{1 0 7}$ with only slightly inferior yields respect to the reactions performed with $\mathrm{TfOH}$.

A facile synthesis of 1,1-disubstituted isoindolines derivatives was achieved by Kobayashi et al. via intramolecular cyclization of 2-(acetylaminomethyl)styrenes 108 (Scheme 39). ${ }^{125}$ Treatment of these compounds with iodine in the presence of sodium hydrogenocarbonate in acetonitrile resulted in a regioselective conversion to 1-iodomethylisoindolines in good yields. In this case, $\mathrm{I}_{2}$ acted as Lewis acid and added to the double bond. Isoindoline nucleus is formed through the nucleophylic attack of the amine moiety. Products 109 can be further transformed by reduction with $n$ - $\mathrm{Bu}_{3} \mathrm{SnH}$ or conversion into the corresponding 1-sulfenylmethyl derivatives by means of treatment with sodium thiolates.

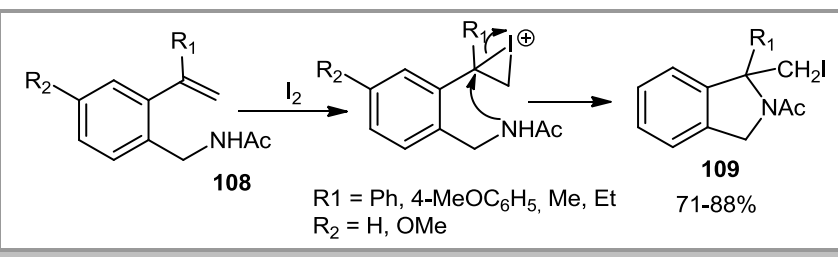

Scheme 39 Intramolecular iodoamination of 2-vinylbenzylamine derivatives.

Another example of intramolecular hydroamination promoted by a Lewis acid, was described by Stephan's group in 2015.126 Treatment of N-(2-ethynylbenzyl)aniline $\mathbf{1 1 0}$ with 10\% tris (perfluorophenyl)borane $\left(\mathrm{B}\left(\mathrm{C}_{6} \mathrm{~F}_{5}\right)_{3}\right)$ in toluene, under hydrogen 
pressure, gave 1-methyl-2-phenylisoindoline 111 in 70\% yield (Scheme 40).

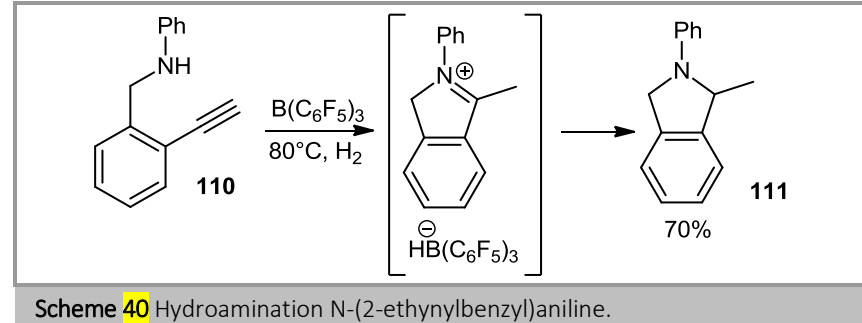

Asymmetric hydroamination was obtained by Tomioka et al. reacting aminoalkenes $\mathbf{1 1 2}$ with chiral bisoxazoline and LDA in toluene at $0^{\circ} \mathrm{C}$ (Scheme 41). ${ }^{127}$ The substituents on the amine and olefin moieties played a fundamental role on the reaction efficiency and enantioselectivity. Indeed, the reactions of N-methyl or N-allyl aminoalkenes with a phenyl group on the double bond afforded the isoindolines derivatives $\mathbf{1 1 3}$ with high yields and enantiomeric excesses, while the reactions performed with a terminal alkene derivative generated the cyclization product $\mathbf{1 1 4}$ in $33 \%$ yield with $43 \%$ ee.

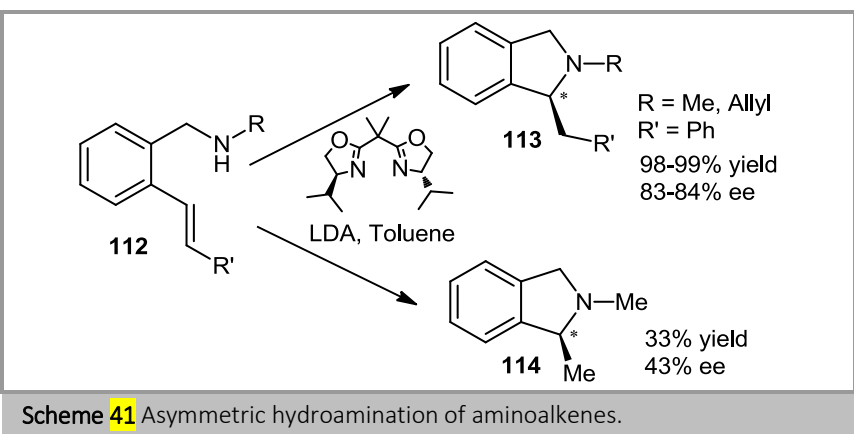

In 1999, Domínguez et al. described the first example of basepromoted cyclization of $N$-acetyl 2-ethynylbenzylamine 115 affording the corresponding 1-methyleneisoindoline 116 with 87\% of yield (Scheme 42). ${ }^{128}$ However, this protocol could not be applied to molecules containing hindered substituents at the benzylic position.

$$
\text { DMF, r.t., } 3 \mathrm{~h}
$$

Scheme $42 \mathrm{NaH}$-promoted intramolecular hydroamination of orthoethynylbenzylamide.

A few years later Sakamoto and co-workers reported an extensive study on the TBAF-promoted intramolecular hydroamination of several $o$-alkynylbenzylamine derivatives. ${ }^{96}$ Interestingly, the authors found that substrates $\mathbf{1 1 7}$ bearing alkyl-substituted triple bond gave preferentially 6-endo-dig ring closure, affording 1,2dihydroisoquinolines 118 as main product, whereas benzyl amides having a TMS- or aryl-substituted triple bond yielded only alkylideneisoindolines 119 (Scheme 43).

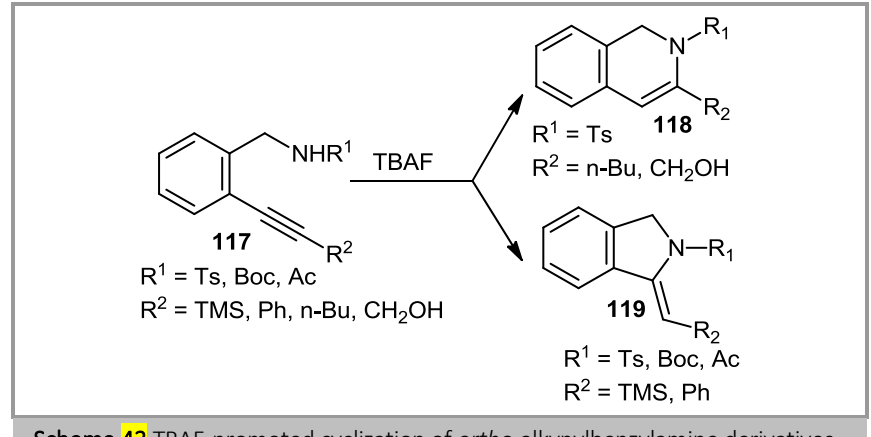

Scheme 43 TBAF-promoted cyclization of ortho-alkynylbenzylamine derivatives.

Moving to transition metal-catalyzed reactions, the only relevant example in the field of hydroaminations was reported by Catalán et al. ${ }^{129}$ in 2013. The authors described the synthesis of many alkylideneisoindolines $\mathbf{1 2 1}$ by gold(I)-promoted intramolecular hydroamination of enantiopure ortho-alkynylbenzyl carbamates 120 bearing a fluorinated alkyl substituent at the benzylic position (Scheme 44).

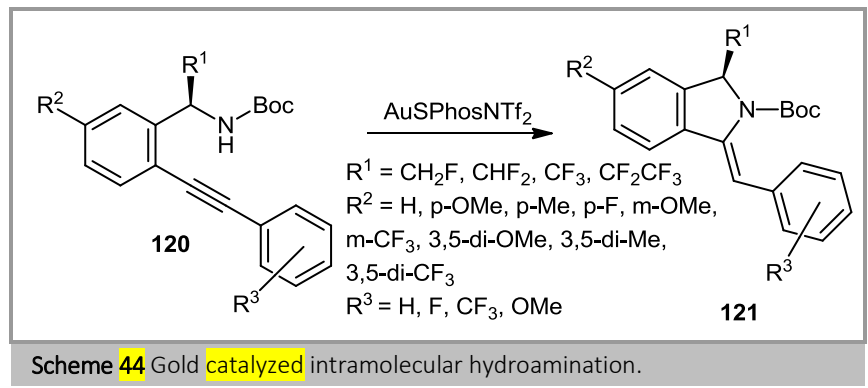

\subsection{Diels-Alder and related reactions}

Isoindolines functionalised on the benzene ring can be generated via intramolecular Diels-Alder (IMDA) cycloadditions and related reactions (Scheme 45).

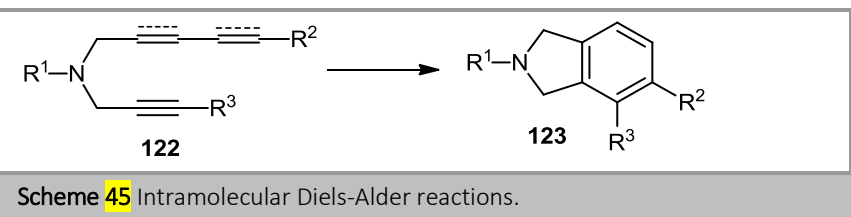

For this purpose Back and co-workers investigated the reactivity of N-pentadienyl-N-propargyl derivatives $\mathbf{1 2 4}$ in order to develop a synthetic approach to isoindoline with diverse substituents on the aromatic moiety. ${ }^{130}$ Indeed, when N-dienyl-N(propargyl)benzenesulfonamides $\mathbf{1 2 4}$ were subjected to IMDA cycloaddition in refluxing anisole with DDQ, the corresponding isoindolines 125 were obtained in excellent yields (Scheme 46).

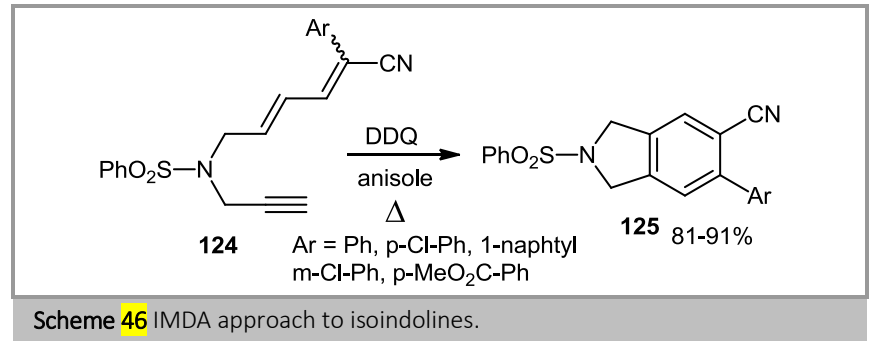


More recently, Wang et al. reported the first case of pentadehydroDiels-Alder (PDDA) reaction applied to the synthesis of 1functionalised isoindolines 129. ${ }^{131}$ The reaction took place with the initial isomerization of tetrayne 126 , followed by rapid PDDA cyclization of $\mathbf{1 2 7}$ and trapping of the intermediate $\mathbf{1 2 8}$ with nitrogen or oxygen nucleophiles (Scheme 47). The product yields were related to the substituent on the $\mathrm{N}$-isoindoline atom and to the structure of the nucleophilic reagent employed. Primary, secondary amines and methanol together with methansulfonamide resulted to be the best substrates yielding the isoindoline nuclei in high quantity.

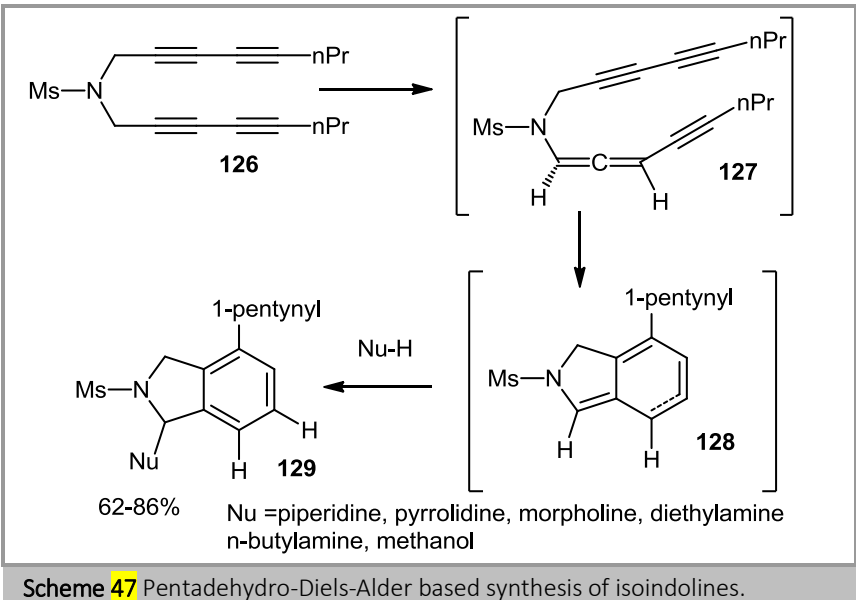

Scheme 47 Pentadehydro-Diels-Alder based synthesis of isoindolines.

The first example of gold-catalyzed formal intramolecular DielsAlder reaction of $\mathrm{N}$-tosylated furanynes $\mathbf{1 3 0}$ was described by Hashmi and co-workers in 2000 (Scheme 48). ${ }^{132}$ When 2 mol\% of $\mathrm{AuCl}_{3}$ were employed, the cyclization took place successfully, whereas no reaction was observed with $\mathrm{AgNO}_{3}, \mathrm{Hg}\left(\mathrm{CLO}_{4}\right)_{2}$, $\mathrm{Pd}_{2} \mathrm{dba}_{3} \cdot \mathrm{CHCl}_{3}, \mathrm{Pd}\left(\mathrm{PPh}_{3}\right)_{4}, \mathrm{Rh}\left(\mathrm{PPh}_{3}\right) \mathrm{Cl}, \mathrm{FeCl}_{3}$ and $\mathrm{InCl}_{3}$.

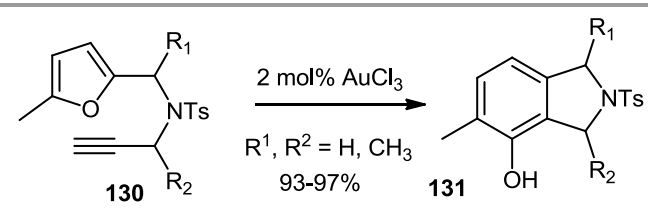

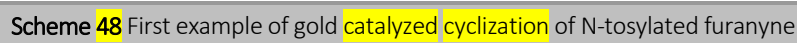

Subsequently the same authors extended their protocol to the reactions of sterically hindered aryl furanynes (Scheme 49).133 Their results clearly indicated that benzene ring bearing two or three substituents such as chlorine, methyl or methoxy groups, did not influence the gold catalyzed cyclization, since 5arylisoindolines $\mathbf{1 3 3}$ were obtained in good yields.

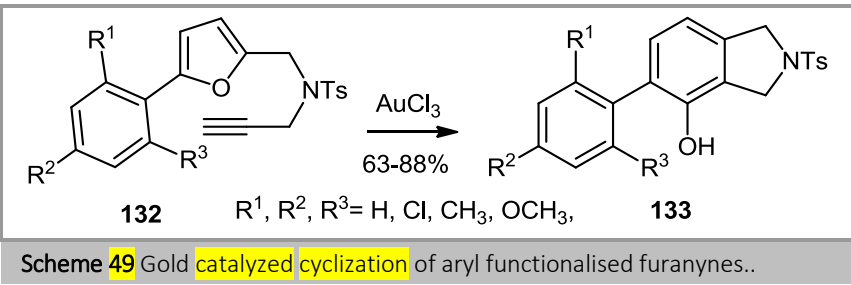

Moreover, the presence of various $\left(\mathrm{Br}, \mathrm{CH}_{2} \mathrm{Cl}_{1} \mathrm{CH}_{2} \mathrm{OAc}, \mathrm{CH}_{2} \mathrm{OPiv}\right)$ substituents on the furan ring proved to be well tolerated in the gold-catalyzed reactions. ${ }^{134}$ Two years later, Hashmi et al. reported the synthesis of isoindolines 135 possessing a chiral centre at the 1-position starting from enantiomerically pure sulfonamides 134 (Scheme 50). ${ }^{135}$

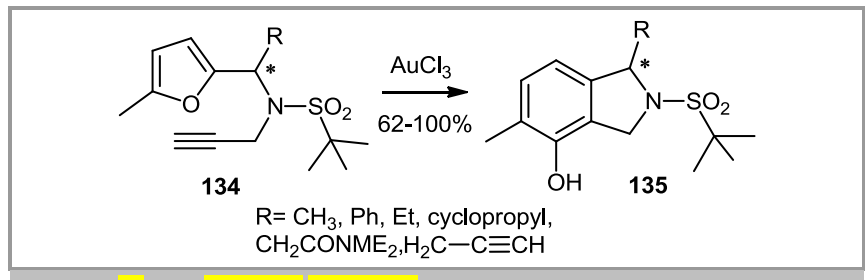

Scheme 50 Gold catalyzed cyclization of chiral sulphonamides.

Finally, the same group developed a one pot sequence for the synthesis of 4-arylated isoindolines starting from $\mathrm{N}$-tosylated furanyne substrates 136, followed by electrophilic bromination with N-bromosuccinimide (NBS) and palladium catalyzed Suzuki coupling. The reactions proceeded with good overall efficiency and showed broad substrate scope (Scheme 51). ${ }^{136}$

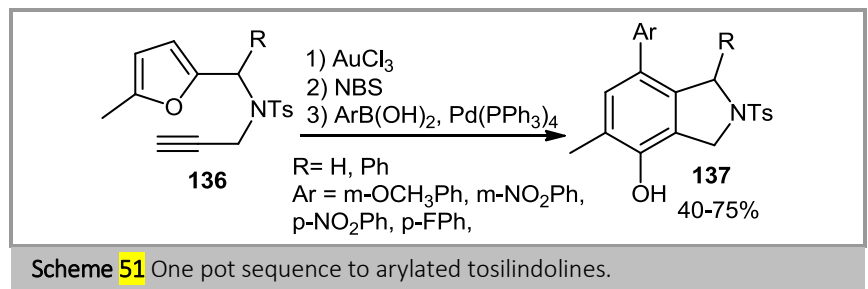

\section{$3.4[2+2+2]$ Cycloaddition reactions}

Transition metal catalyzed $[2+2+2]$ cyclization of three $\pi$ systems has been widely investigated as a valuable synthetic tool for the synthesis of aromatic rings. ${ }^{137}$ In particular the reaction between suitable $\alpha, \omega$-diynes 138 and alkynes can be used for the preparation of isoindoline scaffolds (Scheme 52).

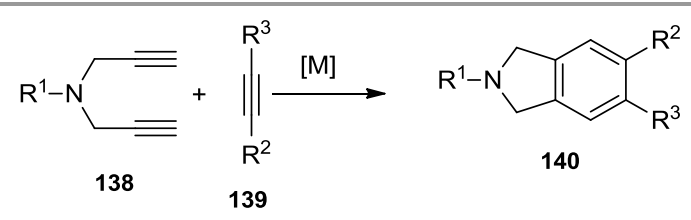

Scheme 52 Synthesis of isoindolines via cycloaddition reactions.

During the past half-century rhodium-based catalysts have been one of the most commonly used catalysts for [2+2+2] cycloaddition of alkynes. ${ }^{138}$ One of the first example of rhodium catalyzed cyclization was reported in 1982 by Grigg and coworkers who used Wilkinson's catalyst $\left[\left(\mathrm{PPh}_{3}\right)_{3} \mathrm{RhCl}\right]$ in the cocyclization of diynes 141 with excess of monoacetylene. ${ }^{39 a}$ In particular, dipropargyl acetamide was converted into the corresponding isoindoline with $76 \%$ yield (Scheme 53). The reaction showed good chemoselectivity with no detectable trimerization of the monoacetylene.

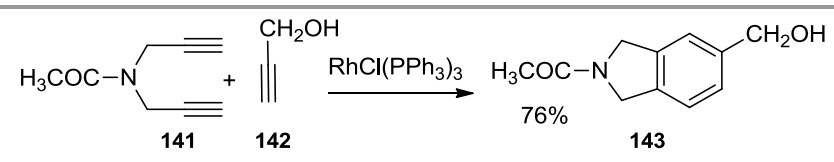

Scheme 53 Grigg's first example of cycloaddition between dipropargyl acetamide and 2-propynol. 
The same catalyst was used by Roglans and co-workers in [2+2+2] cycloadditions between $\mathrm{N}$-tosylated diynes 144 and alkynes 145 bearing a phenylalanine protected amino acid group (Scheme 54). ${ }^{44}$ The reactions were carried out in an environmentally friendly solvent such as ethanol and afforded the functionalised isoindolines $\mathbf{1 4 6}$ with high yields.

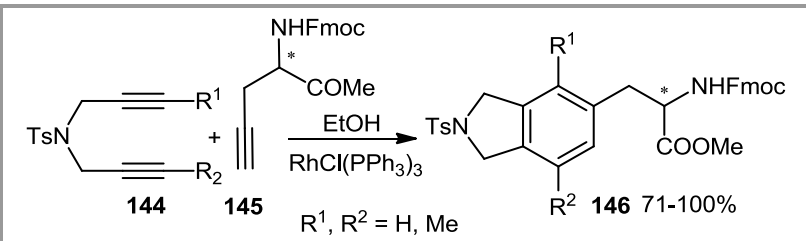

Scheme 54 Cycloadditions between $\mathrm{N}$-tosylated diynes and functionalised alkynes.

Solid-phase reactions technique was applied to the synthesis of isoindolines via $\left[\left(\mathrm{PPh}_{3}\right)_{3} \mathrm{RhCl}\right]$-catalyzed cyclization between resin supported dipropargyl amines and alkynes 147 (Scheme 55). 139

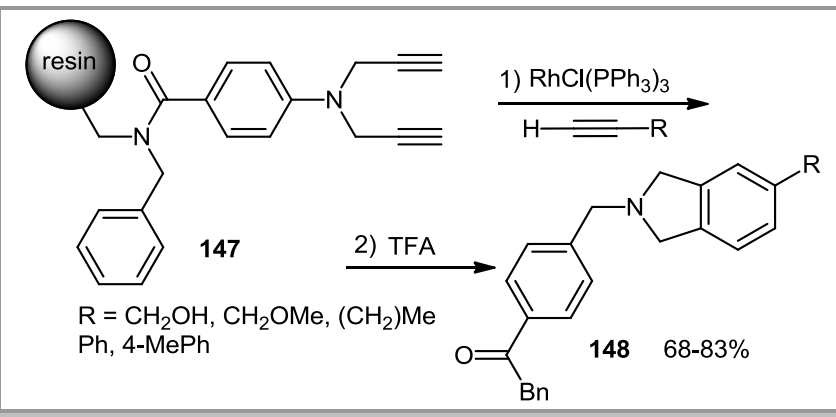

Scheme 55 Synthesis of isoindolines via solid-phase reactions.

Products were cleaved from the resin by treatment with TFA. Terminal alkynes gave better yields than internal ones, possibly due to steric factors.

A few years later, Deiters at al. reported the [( $\left.\left.\mathrm{PPh}_{3}\right)_{3} \mathrm{RhCl}\right]-$ catalyzed cycloaddition of polystirene-supported 1,6-diynes and alkynes 149.47 The corresponding isoindolines 150 were obtained in excellent yields after deprotection with diluted $\mathrm{HCl}$ (Scheme 56). The experimental conditions used for these solid-supported cyclotrimerization reactions were compatible with a variety of functionalities such as alkyl chains, hydroxyl and alkoxy groups, aromatic rings, cyano and silyl groups, chlorine and esters.

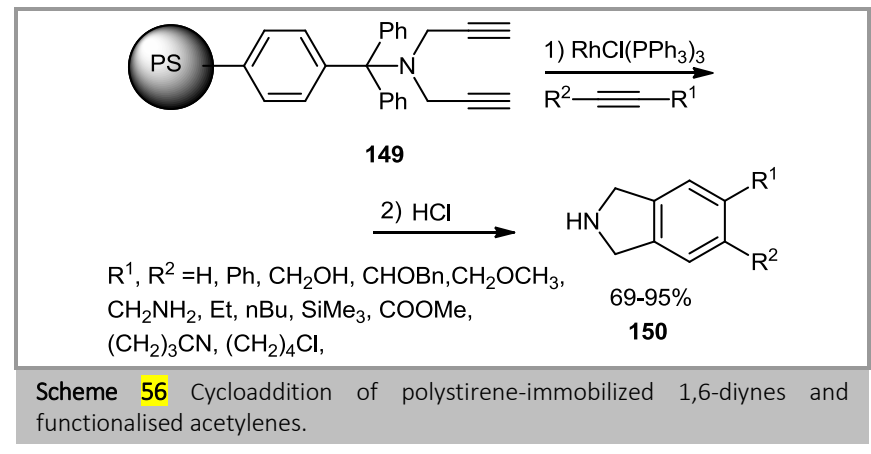

Li and Bonfield developed a multicomponent $[2+2+2]$ cycloaddition promoted by Wilkinson's catalyst. ${ }^{140}$ One-pot reactions of a primary amine with 2 molecules of formaldehyde and 3 molecules of phenyl acetylene produced substituted isoindolines derivatives 152. (Scheme 57).

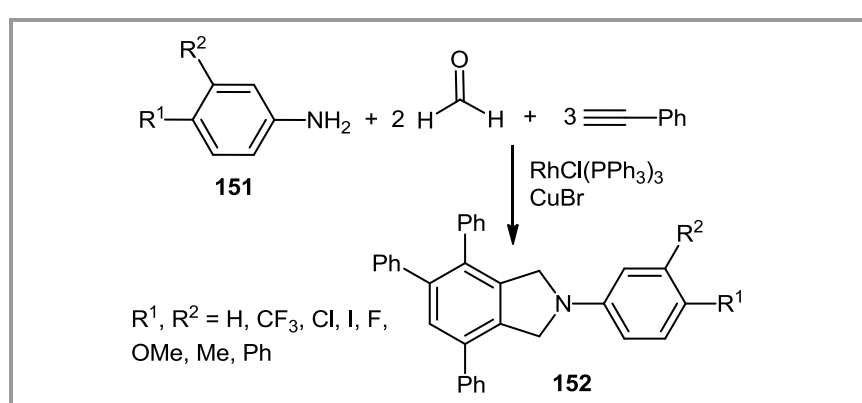

Scheme 57 Synthesis of isoindolines via one-pot multicomponent $[2+2+2]$ cycloaddition reactions.

Very recently $\left[\left(\mathrm{PPh}_{3}\right)_{3} \mathrm{RhCl}\right]$-promoted [2+2+2] co-cyclization has been successfully applied to the synthesis of heat shock protein 90 inhibitor AT 13387, currently used in clinical trials for treatment of gastrointestinal cancers. ${ }^{141}$

Wilkinson's complex is not the only rhodium species that can catalyse the intramolecular $[2+2+2]$ cycloaddition reactions of alkynes and diynes. For instance $\mathrm{Wu}$ and co-workers reported that $[\mathrm{RhCl}(\mathrm{cod})]_{2}$ was able to promote the $[2+2+2]$ cyclotrimerization of terminal dipropargyl tosylamide 153 and alkynes at room temperature in water/THF mixed solvent (Scheme 58). ${ }^{142}$

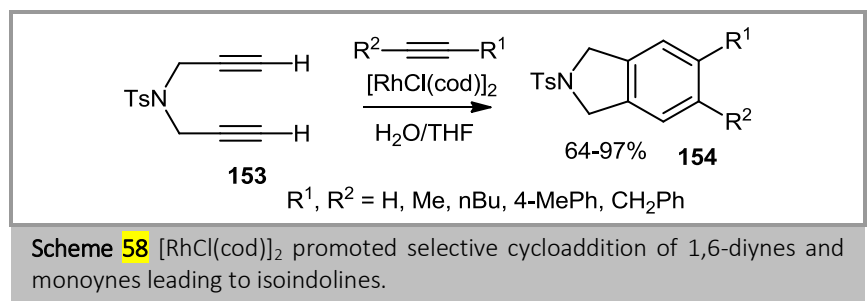

Another simple procedure for the [2+2+2] cycloaddition of $\alpha, \omega$ diynes and alkynes in water was described by Tsai and coworkers. ${ }^{51}$ The authors reported that $[\mathrm{RhCl}(\mathrm{cod})]_{2}-2,2$ '-bipyridyl complex, bearing two quaternary ammonium moieties, can be used for the synthesis of $\mathrm{N}$-tosyl isoindoline derivatives 157 in good yields (Scheme 59).

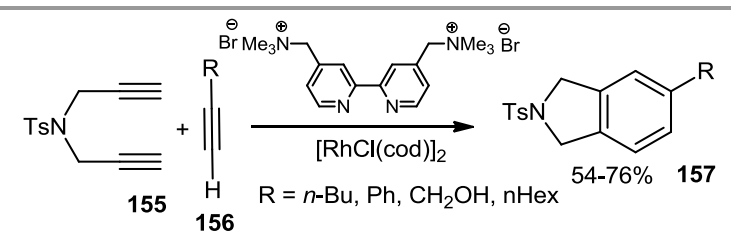

Scheme 59 Rhodium(I)cationic 2,2-bipyridyl-catalyzed [2+2+2] cycloadditions.

In addition to rhodium-based catalysts, other transition metals complexes are able to catalyse $[2+2+2]$ cycloaddition reactions. Michelet and co-workers ${ }^{80,143}$ reported the synthesis of isoindoline scaffolds via $[2+2+2]$ cycloaddition of dipropargyl amides and alkynes employing the stable and practical ionic triply iodobridged iridium-catalyzed $\left[\{\operatorname{Ir}(\mathrm{H})[\text { rac-binap }]\}_{2}(\mu-\mathrm{I})_{3}\right] \mathrm{I}$ in isopropyl alcohol. (Scheme 60). A number of functional groups were tolerated including chlorine, alcohol, ether, cyclopropyl and phenyl. 


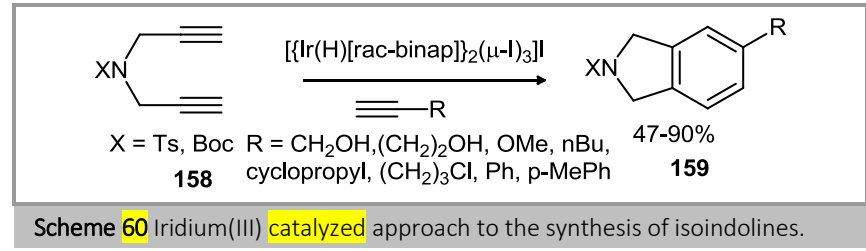

The same group developed ${ }^{80 \mathrm{~b}}$ a solvent free iridium(III)- catalyzed cycloaddition between $\alpha, \omega$-diynes and terminal alkynes which provided access to isoindolines with good yields. Michelet et al. reported ${ }^{78 c}$ also a solvent and ligand free ruthenium trichloridecatalyzed $[2+2+2]$ cycloaddition of diynes and functionalised alkynes. The commercially available, cheap and easy to handle $\mathrm{RuCl}_{3} \cdot \mathrm{nH}_{2} \mathrm{O}$ showed high catalytic activity and selectivity towards the synthesis of N-tosyl and N-Boc isoindoline derivatives.

Mori et al. used Mortreux's catalyst, derived from $\mathrm{Mo}(\mathrm{CO})_{6}$ and p-chlorophenol, for cotrimerization reactions of diyne 160 and internal alkynes to prepare poly-substituted isoindolines in moderate yields (Scheme 61). ${ }^{144}$

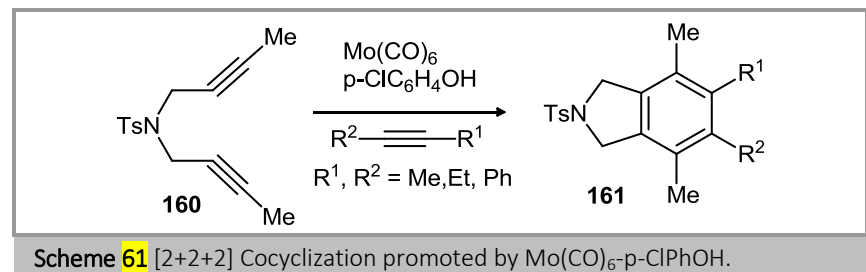

The same authors reported a catalytic asymmetric synthesis of isoindolines via nickel $(0)$ catalyzed [2+2+2] cocyclization of triynes 162 and excess acetylene (Scheme 62). $\mathrm{Ni}(\operatorname{cod})_{2}$ and a chiral ligand promoted the synthesis of isoindolines 163 with good yields an enantiomeric excess. ${ }^{145}$

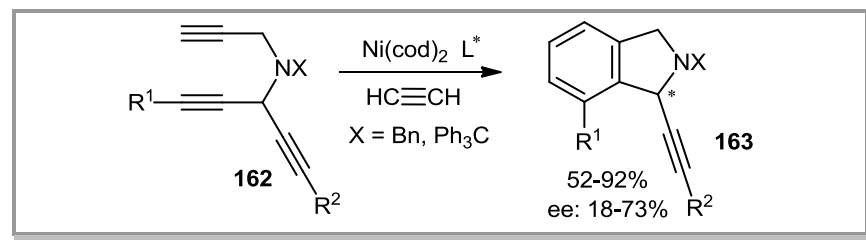

Scheme 62 Synthesis of isoindolines via nickel( 0$)$ catalyzed $[2+2+2]$ cocyclization between triynes and acetylene.

Cheng and co-workers described ${ }^{65}$ the first example of regio and chemoselective $[2+2+2]$ cycloaddition reactions between 1,7heptadiynes 164 and allenes 165 in the presence of $\mathrm{CoI}_{2}\left(\mathrm{PPh}_{3}\right)_{2} / \mathrm{Zn}$ system. $\mathrm{N}$-tosylated isoindolines were obtained in satisfactory yields as depicted in Scheme 63.

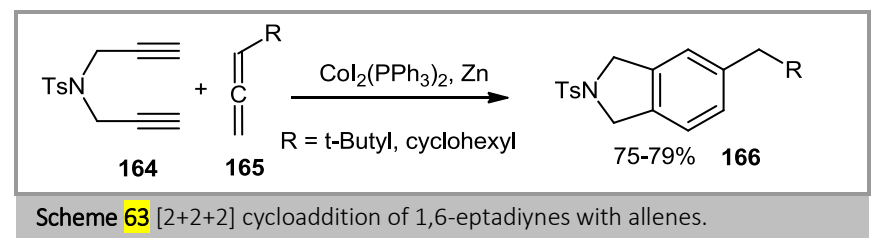

Finally, a different approach to isoindolines was described by Mori et al. ${ }^{146}$ The reaction between nitrogen-containing acetylenes 167, and a chromium carbene complex under carbon monoxide atmosphere, produced isoindolines through a $[2+2+1+1]$ cocyclization. The experimental reaction conditions were optimised for 4-methyl-N,N-di(prop-2-yn-1-yl)benzenesulfonamide (Scheme
$64, \mathrm{R}=\mathrm{H}$ ) and then extended to internal diynes which generated isoindolines 168 having three substituents on the aromatic ring in good yields.

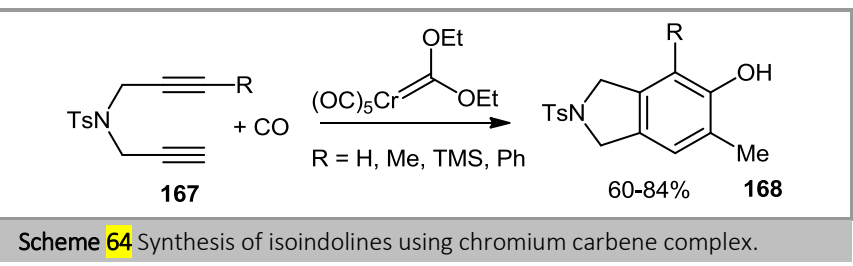

\subsection{Tandem carbonylative Sonogashira-cyclization reactions}

The only example of palladium-catalyzed tandem carbonylative Sonogashira-cyclization reaction applied to the synthesis of alkylideneisoindoline ring was reported very recently by Aronica et al. ${ }^{147}$ 2-Ethynylbenzylamine could not be used directly as substrate, since its reaction with iodobenzene did not give any isoindoline product, although a total consumption of reagents was observed. As a consequence the authors protected the amine moiety with tert-butyloxycarbonyl (Boc) and tosyl (Ts) groups. When $N$-(2-ethynylbenzyl)-4-methylbenzenesulfonamide 169 was used, the reaction took place with complete chemo- and stereoselectivity resulting in the exclusive formation of the fivemembered isoindolines derivatives $\mathbf{1 7 0}$ with an $(E)$ configuration (Scheme 65).

The protocol could be extended to iodoarenes characterised by different functional groups such electron donating (2-OMe, 4-OMe, 2-naphtyl) or electron withdrawing (2-Cl, 4-CN) substituents. A quantitative conversion of the reagents was detected in all cases affording the corresponding (E)-1-carbonylmethyleneisoindoline pure products with good yields $(55-72 \%)$.

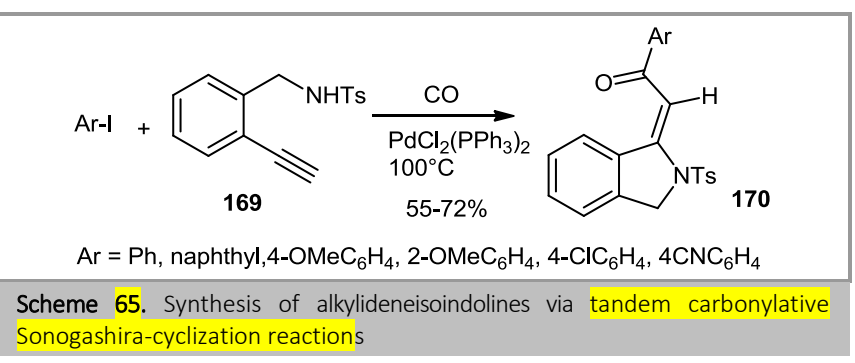

\section{Conclusions}

In this review we highlighted the most significant synthetic strategies described in the literature for the synthesis of phathalans and isoindolines via cyclization reactions. The majority of this methods require $\mathrm{O}$ - or $\mathrm{N}$-functionalised compounds. Two principal cyclization pathways can be involved: i) a benzene ring possessing the suitable substituent may undergo a cyclization reaction which forms the pirrolidine and the furan ring; ii) a polyunsaturated ether or amine derivative can rearrange generating the heterocyclic nucleus. Many of these transformations require a transition metal catalyst or have to be promoted by acid or basic reagents. In a few cases solid-phase techniques have been also applied to the synthesis of both heterocycles.

Considering that isoindolines and 1,3-dihydoisobenzofuran have been recognized as privileged structure due to their 
presence in many bioactive molecules, we hope that this short review can stimulate further research in the field of the synthesis of these compounds such as the investigation on the use of milder experimental conditions and of heterogeneous metal catalysts in order to improve the "greenness" of these processes.

\section{Funding Information}

University of Pisa (PRA_2017_28) is gratefully acknowledged for funding

\section{References}

(1) Harper, J. K.; Arif, A. M.; Ford, E. J.; Strobel, G. A.; Porco Jr, J. A.; Tomer, D. P.; Oneill, K. L.; Heider, E. M.; Grant, D. M. Tetrahedron 2003, 59, 2471.

(2) Pollock, B. G. Expert Opin. Pharmacother. 2001, 2, 681.

(3) (a) Jiaang, W.-T.; Chen, Y.-S.; Hsu, T.; Wu, S.-H.; Chien, C.-H.; Chang, C.-N.; Chang, S.-P.; Lee, S.-J.; Chen, X. Bioorg. Med. Chem. Lett. 2005, 15, 687. (b) Van der Veken, P.; Soroka, A.; Brandt, I.; Chen, Y.-S.; Maes, M.B.; Lambeir, A.-M.; Chen, X.; Haemers, A.; Scharpé, S.; Augustyns, K.; De Meester, I. J. Med. Chem. 2007, 50, 5568. (c) Van Goethem, S.; Van der Veken, P.; Dubois, V.; Soroka, A.; Lambeir, A.-M.; Chen, X.; Haemers, A.; Scharpé, S.; De Meester, I.; Augustyns, K. Bioorg. Med. Chem. Lett. 2008, 18, 4159. (d) Kung, P.-P.; Huang, B.; Zhang, G.; Zhou, J. Z.; Wang, J.; Digits, J. A.; Skaptason, J.; Yamazaki, S.; Neul, D.; Zientek, M.; Elleraas, J.; Mehta, P.; Yin, M.-J.; Hickey, M. J.; Gajiwala, K. S.; Rodgers, C.; Davies, J. F.; Gehring, M. R. J. Med. Chem. 2010, 53, 499. (e) Tsai, T.-Y.; Yeh, T.-K.; Chen, X.; Hsu, T.; Jao, Y.-C.; Huang, C.-H.; Song, J.-S.; Huang, Y.-C.; Chien, C.-H.; Chiu, J.-H.; Yen, S.-C.; Tang, H.-K.; Chao, Y.-S.; Jiaang, W.-T. J. Med. Chem. 2010, 53, 6572. (f) Kato, N.; Oka, M.; Murase, T.; Yoshida, M.; Sakairi, M.; Yakufu, M.; Yamashita, S.; Yasuda, Y.; Yoshikawa, A.; Hayashi, Y.; Shirai, M.; Mizuno, Y.; Takeuchi, M.; Makino, M.; Takeda, M.; Kakigami, T. Org. Med. Chem. Lett. 2011, 1, 7. (g) Van Goethem, S.; Matheeussen, V.; Joossens, J.; Lambeir, A.-M.; Chen, X.; De Meester, I.; Haemers, A.; Augustyns, K.; Van der Veken, P. J. Med. Chem. 2011, 54, 5737. (h) Ren, J.; Li, J.; Wang, Y.; Chen, W.; Shen, A.; Liu, H.; Chen, D.; Cao, D.; Li, Y.; Zhang, N.; Xu, Y.; Geng, M.; He, J.; Xiong, B.; Shen, J. Bioorg. Med. Chem. Lett. 2014, 24, 2525. (i) Tso, S.-C.; Qi, X.; Gui, W.-J.; Wu, C.Y.; Chuang, J. L.; Wernstedt-Asterholm, I.; Morlock, L. K.; Owens, K. R.; Scherer, P. E.; Williams, N. S.; Tambar, U. K.; Wynn, R. M.; Chuang, D. T. J. Biol. Chem. 2014, 289, 4432. (j) Tso, S.-C.; Lou, M.; Wu, C.-Y.; Gui, W.J.; Chuang, J. L.; Morlock, L. K.; Williams, N. S.; Wynn, R. M.; Qi, X.; Chuang, D. T. J. Med. Chem. 2017, 60, 1142.

(4) (a) Pinard, E.; Alberati, D.; Bender, M.; Borroni, E.; Brom, V.; Burner, S.; Fischer, H.; Hainzl, D.; Halm, R.; Hauser, N.; Jolidon, S.; Lengyel, J.; Marty, H.-P.; Meyer, T.; Moreau, J.-L.; Mory, R.; Narquizian, R.; Norcross, R. D.; Schmid, P.; Wermuth, R.; Zimmerli, D. Bioorg. Med. Chem. Lett. 2010, 20, 6960. (b) Andrade-Jorge, E.; Bahena-Herrera, J. R.; Garcia-Gamez, J.; Padilla-Martínez, I. I.; Trujillo-Ferrara, J. G. Med. Chem. Res. 2017, 26, 2420.

(5) (a) Berger, D.; Citarella, R.; Dutia, M.; Greenberger, L.; Hallett, W.; Paul, R.; Powell, D. J. Med. Chem. 1999, 42, 2145. (b) Shultz, M.; Fan, J.; Chen, C.; Cho, Y. S.; Davis, N.; Bickford, S.; Buteau, K.; Cao, X.; Holmqvist, M.; Hsu, M.; Jiang, L.; Liu, G.; Lu, Q.; Patel, C.; Suresh, J. R.; Selvaraj, M.; Urban, L.; Wang, P.; Yan-Neale, Y.; Whitehead, L.; Zhang, H.; Zhou, L.; Atadja, P. Bioorg. Med. Chem. Lett. 2011, 21, 4909. (c) Trejo Muñoz, C. R.; Mancilla Percino, T.; Mera Jiménez, E.; Correa-Basurto, J.; Trujillo Ferrara, J. G. Med. Chem. Res. 2013, 22, 4039. (d) Trejo Muñoz, C. R.; Jiménez, E. M.; Pinto-Almazán, R.; Gandarilla, J. A. D.; Correa-Basurto, J.; Trujillo-Ferrara, J. G.; Guerra-Araiza, C.; Rohana, P. T.; Percino, T. M. Med. Chem. Res. 2014, 23, 3227. (e) Mancilla-Percino, T.; Trejo-Muñoz, C. R.; Díaz-Gandarilla, J. A.; Talamás-Rohana, P.; Guzmán Ramírez, J. E.; Cervantes, J.; Figueroa Ortíz, A. Arch. Pharm. 2016, 349, 175.

(6) Radtke, V.; Erk, P.; Sens, B. In Isoindoline Pigments, Smith, H. M., Ed.; Wiley-VCH, 2002, 211.

(7) (a) Almena, J.; Foubelo, F.; Yus, M. Tetrahedron 1995, 51, 3351. (b) Azzena, U.; Demartis, S.; Fiori, M. G.; Melloni, G.; Pisano, L. Tetrahedron
Lett. 1995, 36, 8123. (c) Azzena, U.; Demartis, S.; Melloni, G. J. Org. Chem. 1996, 61, 4913. (d) García, D.; Foubelo, F.; Yus, M. Tetrahedron 2008, 64, 4275 .

(8) Almena, J.; Foubelo, F.; Yus, M. Tetrahedron 1996, 52, 8545.

(9) Li, D. Y.; Shang, X. S.; Chen, G. R.; Liu, P. N. Org. Lett. 2013, 15, 3848.

(10)Siyang, H. X.; Wu, X. R.; Liu, H. L.; Wu, X. Y.; Liu, P. N. J. Org. Chem. 2014, 79, 1505 .

(11)Sośnicki, J. G. Monatsh. Chem. 2000, 131, 475.

(12)Ohmura, T.; Kijima, A.; Suginome, M. Org. Lett. 2011, 13, 1238.

(13) Galletti, P.; Funiciello, F.; Soldati, R.; Giacomini, D. Adv. Synth. Catal. 2015, 357, 1840.

(14)(a) Larghi, E. L.; Kaufman, T. S. Synthesis 2006, 2006, 187. (b) Larghi, E. L.; Kaufman, T. S. Eur. J. Org. Chem. 2011, 2011, 5195.

(15)Guiso, M.; Betrow, A.; Marra, C. Eur. J. Org. Chem. 2008, 2008, 1967.

(16)Khorsandi, Z.; Khosropour, A. R.; Mirkhani, V.; MohammadpoorBaltork, I.; Moghadam, M.; Tangestaninejad, S. Tetrahedron Lett. 2011, $52,1213$.

(17)Iwai, I.; Ide, J. Chem. Pharm. Bull. 1964, 12, 1094.

(18)(a) Garratt, P. J.; Neoh, S. B. J. Am. Chem. Soc. 1975, 97, 3255. (b) Garratt, P. J.; Neoh, S. B. J. Org. Chem. 1979, 44, 2667.

(19)(a) Mondal, S.; Maji, M.; Basak, A. Tetrahedron Lett. 2011, 52, 1183. (b) Addy, P. S.; Dutta, S.; Biradha, K.; Basak, A. Tetrahedron Lett. 2012, 53, 19. (c) Mitra, T.; Das, J.; Maji, M.; Das, R.; Das, U. K.; Chattaraj, P. K.; Basak, A. RSC Adv. 2013, 3, 19844. (d) Panja, A.; Ghosh, D.; Basak, A. Bioorg. Med. Chem. Lett. 2013, 23, 893. (e) Das, J.; Mukherjee, R.; Basak, A. J. Org. Chem. 2014, 79, 3789. (f) Ghosh, D.; Biswas, S.; Ghosh, K.; Basak, A. Tetrahedron Lett. 2014, 55, 3934. (g) Panja, A.; Banerjee, D. R.; Basak, A. RSC Adv. 2014, 4, 54235. (h) Das, J.; Bag, S. S.; Basak, A. J. Org. Chem. 2016, 81, 4623.

(20)Shealy, Y. F.; Riordan, J. M.; Frye, J. L.; Campbell, S. R. Tetrahedron 1996, 52, 405.

(21)Fernandez de la Pradilla, R.; Baile, R.; Tortosa, M. Chem. Commun. 2003, 2476.

(22)Hayakawa, K.; Yodo, M.; Ohsuki, S.; Kanematsu, K. J. Am. Chem. Soc. 1984, 106, 6735.

(23)Kramer, N. J.; Hoang, T. T.; Dudley, G. B. Org. Lett. 2017, 19, 4636.

(24)Lu, L.; Liu, X.-Y.; Shu, X.-Z.; Yang, K.; Ji, K.-G.; Liang, Y.-M. J. Org. Chem. 2009, 74, 474.

(25)Shen, R.-W.; Yang, J.-J.; Zhang, L.-X. Chin. Chem. Lett. 2015, $26,73$. (26)(a) Wu, H.-J; Shao, W.-D.; Ying, F.-H. Tetrahedron Lett. 1994, 35, 729. (b) Wu, H.-J.; Ying, F.-H.; Shao, W.-D. J. Org. Chem. 1995, 60, 6168. (c) Wu, H.-J.; Yen, C.-H.; Chuang, C.-T. J. Org. Chem. 1998, 63, 5064.

(27)Torosyan, G. O. Russ. J. Org. Chem. 2002, 38, 1489.

(28)Karaarslan, M.; Gokturk, E.; Demircan, A. J. Chem. Res. 2007, 2007, 117.

(29) Martín-Matute, B.; Cárdenas, D. J.; Echavarren, A. M. Angew. Chem. Int. Ed. 2001, 40, 4754.

(30)Hashmi, A. S. K.; Wölfle, M.; Ata, F.; Hamzic, M.; Salathé, R.; Frey, W. Adv. Synth. Catal. 2006, 348, 2501.

(31)Wang, K.-P.; Yun, S. Y.; Mamidipalli, P.; Lee, D. Chem. Sci. 2013, 4, 3205.

(32)Karmakar, R.; Ghorai, S.; Xia, Y.; Lee, D. Molecules 2015, 20, 15862. (33) Niu, D.; Wang, T.; Woods, B. P.; Hoye, T. R. Org. Lett. 2014, 16, 254. (34)Karmakar, R.; Wang, K.-P.; Yun, S. Y.; Mamidipalli, P.; Lee, D. Org. Biomol. Chem. 2016, 14, 4782.

(35)Zhang, J.; Niu, D.; Brinker, V. A.; Hoye, T. R. Org. Lett. 2016, 18, 5596.

(36)Chen, J.; Palani, V.; Hoye, T. R. J. Am. Chem. Soc. 2016, 138, 4318.

(37)Watanabe, T.; Curran, D. P.; Taniguchi, T. Org. Lett. 2015, 17, 3450.

(38)Ghorai, S.; Lee, D. Tetrahedron 2017, 73, 4062.

(39)(a) Grigg, R.; Scott, R.; Stevenson, P. Tetrahedron Lett. 1982, 23, 2691. (b) Grigg, R.; Scott, R.; Stevenson, P. J. Chem. Soc., Perkin Trans. 1 1988, 1357.

(40)Clayden, J.; Moran, W. J. Org. Biomol. Chem. 2007, 5, 1028.

(41)(a) Tanaka, K.; Hara, H.; Nishida, G.; Hirano, M. Org. Lett. 2007, 9, 1907. (b) Konno, T.; Moriyasu, K.; Kinugawa, R.; Ishihara, T. Org. Biomol. Chem. 2010, 8, 1718. 
(42)(a) McDonald, F. E.; Zhu, H. Y. H.; Holmquist, C. R. J. Am. Chem. Soc. 1995, 117, 6605. (b) Suryawanshi, S. B.; Dushing, M. P.; Gonnade, R. G.; Ramana, C. V. Tetrahedron 2010, 66, 6085.

(43)(a) Kondoh, A.; Yorimitsu, H.; Oshima, K. J. Am. Chem. Soc. 2007, 129, 6996. (b) Kobatake, T.; Kondoh, A.; Yoshida, S.; Yorimitsu, H.; Oshima, K. Chem. Asian J. 2008, 3, 1613.

(44) Garcia, L.; Pla-Quintana, A.; Roglans, A. Org. Biomol. Chem. 2009, 7 , 5020.

(45)Hara, H.; Hirano, M.; Tanaka, K. Tetrahedron 2009, 65, 5093.

(46)Fang, X.; Sun, J.; Tong, X. Chem. Commun. 2010, 46, 3800.

(47)Young, D. D.; Senaiar, R. S.; Deiters, A. Chem. Eur. J. 2006, 12, 5563.

(48)Uchimura, H.; Ito, J.-i.; Iwasa, S.; Nishiyama, H. J. Organomet. Chem. 2007, 692, 481.

(49)Brun, S.; Parera, M.; Pla-Quintana, A.; Roglans, A.; León, T.; Achard, T.; Solà, J.; Verdaguer, X.; Riera, A. Tetrahedron 2010, 66, 9032.

(50)Kinoshita, H.; Shinokubo, H.; Oshima, K. J. Am. Chem. Soc. 2003 125, 7784.

(51)Wang, Y.-H.; Huang, S.-H.; Lin, T.-C.; Tsai, F.-Y. Tetrahedron 2010 $66,7136$.

(52)Fernández, M.; Ferré, M.; Pla-Quintana, A.; Parella, T.; Pleixats, R.; Roglans, A. Eur. J. Org. Chem. 2014, 2014, 6242.

(53)Tanaka, K.; Takeishi, K.; Noguchi, K. J. Am. Chem. Soc. 2006, 128, 4586.

(54)Nishida, G.; Suzuki, N.; Noguchi, K.; Tanaka, K. Org. Lett. 2006, 8 , 3489 .

(55)(a) Doherty, S.; Knight, J. G.; Smyth, C. H.; Harrington, R. W.; Clegg, W. Org. Lett. 2007, 9, 4925. (b) Nishida, G.; Noguchi, K.; Hirano, M.; Tanaka, K. Angew. Chem. Int. Ed. 2007, 46, 3951. (c) Mori, F.; Fukawa, N.; Noguchi, K.; Tanaka, K. Org. Lett. 2011, 13, 362.

(56)Nishida, G.; Ogaki, S.; Yusa, Y.; Yokozawa, T.; Noguchi, K.; Tanaka, K. Org. Lett. 2008, 10, 2849.

(57)(a) Oppenheimer, J.; Hsung, R. P.; Figueroa, R.; Johnson, W. L. Org. Lett. 2007, 9, 3969. (b) Oppenheimer, J.; Johnson, W. L.; Figueroa, R.; Hayashi, R.; Hsung, R. P. Tetrahedron 2009, 65, 5001.

(58) Nishida, G.; Noguchi, K.; Hirano, M.; Tanaka, K. Angew. Chem. Int Ed. 2008, 47, 3410 .

(59)Suda, T.; Noguchi, K.; Hirano, M.; Tanaka, K. Chem. Eur. J. 2008, 14, 6593.

(60)Sakiyama, N.; Hojo, D.; Noguchi, K.; Tanaka, K. Chem. Eur. J. 2011 17,1428 .

(61)Ogaki, S.; Shibata, Y.; Noguchi, K.; Tanaka, K. J. Org. Chem. 2011, 76, 1926.

(62)Sugihara, T.; Wakabayashi, A.; Nagai, Y.; Takao, H.; Imagawa, H.; Nishizawa, M. Chem. Commun. 2002, 576.

(63)Gandon, V.; Leca, D.; Aechtner, T.; Vollhardt, K. P. C.; Malacria, M.; Aubert, C. Org. Lett. 2004, 6, 3405.

(64)Young, D. D.; Deiters, A. Angew. Chem. Int. Ed. 2007, 46, 5187.

(65)Wu, M.-S.; Shanmugasundaram, M.; Cheng, C.-H. Chem. Commun. 2003, 718 .

(66)Turek, P.; Kotora, M.; Hocek, M.; Císařová, I. Tetrahedron Lett. 2003, 44, 785.

(67)Jungk, P.; Fischer, F.; Thiel, I.; Hapke, M. J. Org. Chem. 2015, 80, 9781.

(68)Thiel, I.; Jiao, H.; Spannenberg, A.; Hapke, M. Chem. Eur. J. 2013, 19, 2548.

(69)Geny, A.; Agenet, N.; Iannazzo, L.; Malacria, M.; Aubert, C.; Gandon, V. Angew. Chem. Int. Ed. 2009, 48, 1810.

(70)Goswami, A.; Ito, T.; Okamoto, S. Adv. Synth. Catal. 2007, 349 2368.

(71)Sugiyama, Y.-k.; Kariwa, T.; Sakurada, T.; Okamoto, S. Synlett 2012 23,2549 .

(72)(a) Jungk, P.; Fischer, F.; Hapke, M. ACS Catal. 2016, 6, 3025. (b) Jungk, P.; Täufer, T.; Thiel, I.; Hapke, M. Synthesis 2016, 48, 2026.

(73)Yamamoto, Y.; Ogawa, R.; Itoh, K. Chem. Commun. 2000, 549.

(74)Yamamoto, Y.; Arakawa, T.; Ogawa, R.; Itoh, K. J. Am. Chem. Soc. 2003, 125, 12143.

(75)Yamamoto, Y.; Hashimoto, T.; Hattori, K.; Kikuchi, M.; Nishiyama, H. Org. Lett. 2006, 8, 3565.
(76)Yamamoto, Y.; Hattori, K.; Ishii, J.-i.; Nishiyama, H. Tetrahedron 2006, 62, 4294.

(77)(a) Yamamoto, Y.; Hattori, K.; Nishiyama, H. J. Am. Chem. Soc. 2006, 128, 8336. (b) Yamamoto, Y.; Hattori, K. Tetrahedron 2008, 64, 847.

(78)(a) Mallagaray, Á.; Medina, S.; Domínguez, G.; Pérez-Castells, J. Synlett 2010, 2010, 2114. (b) Yuan, W.; Wei, Y.; Shi, M. ChemistryOpen 2013, 2, 63. (c) Jacquet, J.; Auvinet, A.-L.; Mandadapu, A. K.; Haddad, M.; Ratovelomanana-Vidal, V.; Michelet, V. Adv. Synth. Catal. 2015, 357, 1387

(79)(a) Takeuchi, R.; Tanaka, S.; Nakaya, Y. Tetrahedron Lett. 2001, 42, 2991. (b) Kezuka, S.; Tanaka, S.; Ohe, T.; Nakaya, Y.; Takeuchi, R. J. Org. Chem. 2006, 71, 543.

(80)(a) Auvinet, A.-L.; Ez-Zoubir, M.; Bompard, S.; Vitale, M. R.; Brown, J. A.; Michelet, V.; Ratovelomanana-Vidal, V. ChemCatChem 2013, 5, 2389. (b) Auvinet, A.-L.; Michelet, V.; Ratovelomanana-Vidal, V. Synthesis 2013, 45, 2003.

(81)Masuyama, Y.; Miyazaki, K.; Suzuki, N. Asian J. Org. Chem. 2013, 2, 750.

(82)(a) Shibata, T.; Fujimoto, T.; Yokota, K.; Takagi, K. J. Am. Chem. Soc. 2004, 126, 8382. (b) Shibata, T.; Yoshida, S.; Arai, Y.; Otsuka, M.; Endo, K. Tetrahedron 2008, 64, 821.

(83)(a) Ikeda, S.-i.; Watanabe, H.; Sato, Y. J. Org. Chem. 1998, 63, 7026. (b) Jeevanandam, A.; Korivi, R. P.; Huang, I. w.; Cheng, C.-H. Org. Lett. 2002, 4, 807. (c) Turek, P.; Kotora, M.; Tišlerová, I.; Hocek, M.; Votruba, I.; Císařová, I. J. Org. Chem. 2004, 69, 9224. (d) Turek, P.; Novák, P.; Pohl, R.; Hocek, M.; Kotora, M. J. Org. Chem. 2006, 71, 8978. (e) Lu, X.; Pan, B.; Wu, F.; Xin, X.; Wan, B. Tetrahedron Lett. 2015, 56, 4753. (f) Pal, S.; Uyeda, C. J. Am. Chem. Soc. 2015, 137, 8042.

(84)(a) Dufková, L.; Císařová, I.; Štepnička, P.; Kotora, M. Eur. J. Org. Chem. 2003, 2003, 2882. (b) Saino, N.; Kogure, D.; Kase, K.; Okamoto, S. J. Organomet. Chem. 2006, 691, 3129. (c) Minakawa, M.; Ishikawa, T.; Namioka, J.; Hirooka, S.; Zhou, B.; Kawatsura, M. RSC Adv. 2014, 4, 41353. (d) Chowdhury, H.; Chatterjee, N.; Goswami, A. Eur. J. Org. Chem. 2015, 2015, 7735. (e) Bhatt, D.; Chowdhury, H.; Goswami, A. Org. Lett. 2017, 19, 3350.

(85)(a) Yamamoto, Y.; Nagata, A.; Nagata, H.; Ando, Y.; Arikawa, Y.; Tatsumi, K.; Itoh, K. Chem. Eur. J. 2003, 9, 2469. (b) Zhou, P.; Zheng, M.; Jiang, H.; Li, X.; Qi, C. J. Org. Chem. 2011, 76, 4759.

(86)Ozerov, O. V.; Patrick, B. O.; Ladipo, F. T. J. Am. Chem. Soc. 2000, $122,6423$.

(87)Capriati, V.; Florio, S.; Luisi, R.; Perna, F. M.; Salomone, A. J. Org. Chem. 2006, 71, 3984

(88)Coppi, D. I.; Salomone, A.; Perna, F. M.; Capriati, V. Angew. Chem. Int. Ed. 2012, 51, 7532.

(89)(a) Bennett, J. M.; Shapiro, J. D.; Choinski, K. N.; Mei, Y.; Aulita, S. M.; Reinheimer, E. W.; Majireck, M. M. Tetrahedron Lett. 2017, 58, 1117. (b) Sun, R.; Jiang, Y.; Tang, X.-Y.; Shi, M. Asian J. Org. Chem. 2017, 6, 83.

(90)Dem'yanovich, V. M.; Shishkina, I. N.; Kuznetsova, A. A.; Potekhin, K. A.; Chesnova, A. V. Russ. J. Org. Chem. 2006, 42, 986.

(91)(a) Parham, W. E.; Bradsher, C. K.; Reames, D. C. J. Org. Chem. 1981, 46, 4804. (b) Delacroix, T.; Bérillon, L.; Cahiez, G.; Knochel, P. J. Org. Chem. 2000, 65, 8108. (c) Martin, C.; Mailliet, P.; Maddaluno, J. J. Org. Chem. 2001, 66, 3797. (d) Mihara, M.; Ishino, Y.; Minakata, S.; Komatsu, M. Synlett 2002, 2002, 1526. (e) Yus, M.; Foubelo, F.; Ferrández, J. V. Tetrahedron 2003, 59, 2083. (f) Panda, B.; Sarkar, T. K. Tetrahedron Lett. 2008, 49, 6701. (g) Zhang, L.; Zhang, W.; Liu, J.; Hu, J. J. Org. Chem. 2009, 74, 2850. (h) Kim, J.; Lee, D.-H.; Kalutharage, N.; Yi, C. S. ACS Catal. 2014, 4, 3881. (i) Arico, F.; Evaristo, S.; Tundo, P. Green Chem. 2015, 17, 1176. (j) Li, D.-Y.; Wei, Y.; Shi, M. Asian J. Org. Chem. 2016, 5, 423.

(92)(a) Chao, B.; Dittmer, D. C. Tetrahedron Lett. 2000, 41, 6001. (b) Kobayashi, K.; Shikata, K.; Fukamachi, S.; Konishi, H. Heterocycles 2008, 75, 599. (c) Luzzio, F. A.; Okoromoba, O. E. Tetrahedron Lett. 2011, 52, 6530. (d) Yuan, H.; Gong, Y. J. Fluorine Chem. 2013, 149, 125. (e) Guo, K.; Chen, X.; Guan, M.; Zhao, Y. Org. Lett. 2015, 17, 1802. (f) Ida, A.; Kitao, K.; Hoshiya, N.; Uenishi, J. i. Tetrahedron Lett. 2015, 56, 1956. (g) Krishna, J.; Niharika, P.; Satyanarayana, G. RSC Adv. 2015, 5, 
26749. (h) Jarrige, L.; Carboni, A.; Dagousset, G.; Levitre, G.; Magnier, E.; Masson, G. Org. Lett. 2016, 18, 2906.

(93) (a) Padwa, A.; Krumpe, K. E.; Weingarten, M. D. J. Org. Chem. 1995 60, 5595. (b) Weingarten, M. D.; Padwa, A. Tetrahedron Lett. 1995, 36, 4717.

(94)Li, D. Y.; Shi, K. J.; Mao, X. F.; Zhao, Z. L.; Wu, X. Y.; Liu, P. N. Tetrahedron 2014, 70, 7022.

(95)Mancuso, R.; Mehta, S.; Gabriele, B.; Salerno, G.; Jenks, W. S.; Larock, R. C. J. Org. Chem. 2010, 75, 897.

(96)Hiroya, K.; Jouka, R.; Kameda, M.; Yasuhara, A.; Sakamoto, T. Tetrahedron 2001, 57, 9697.

(97)Duan, S.; Cress, K.; Waynant, K.; Ramos-Miranda, E.; Herndon, J. W. Tetrahedron 2007, 63, 2959.

(98)Dell'Acqua, M.; Facoetti, D.; Abbiati, G.; Rossi, E. Synthesis 2010, 2010, 2367.

(99)Brinkmann, C.; Barrett, A. G. M.; Hill, M. S.; Procopiou, P. A.; Reid, S. Organometallics 2012, 31, 7287.

(100) (a) Yu, X.; Seo, S.; Marks, T. J. J. Am. Chem. Soc. 2007, 129, 7244. (b) Seo, S.; Yu, X.; Marks, T. J. J. Am. Chem. Soc. 2009, 131, 263. (c) Sun, Y.; Wu, G.; Cen, D.; Chen, Y.; Wang, L. Dalton Trans. 2012, 41, 9682. (d) Martínez, J.; Otero, A.; Lara-Sánchez, A.; Castro-Osma, J. A.; Fernández-Baeza, J.; Sánchez-Barba, L. F.; Rodríguez, A. M. Organometallics 2016, 35, 1802.

(101) Wobser, S. D.; Marks, T. J. Organometallics 2013, 32, 2517.

(102) Villemin, D.; Goussu, D. Heterocycles 1989, 29, 1255.

(103) Chai, Z.; Xie, Z.-F.; Liu, X.-Y.; Zhao, G.; Wang, J.-D. J. Org. Chem. 2008, 73, 2947.

(104) (a) Lu, D.; Zhou, Y.; Li, Y.; Yan, S.; Gong, Y. J. Org. Chem. 2011, 76, 8869. (b) Tomás-Mendivil, E.; Starck, J.; Ortuno, J.-C.; Michelet, V. Org. Lett. 2015, 17, 6126. (c) Cao, Z.; Li, S.; Li, J.; Meng, X.; Zhang, H.; Sun, X.; You, J. New J. Chem. 2016, 40, 8211.

(105) (a) Fürstner, A.; Szillat, H.; Stelzer, F. J. Am. Chem. Soc. 2000, 122, 6785. (b) Fürstner, A.; Stelzer, F.; Szillat, H. J. Am. Chem. Soc. 2001, 123, 11863. (c) Nakamura, I.; Chan, C. S.; Araki, T.; Terada, M.; Yamamoto, Y. Org. Lett. 2008, 10, 309. (d) Nakamura, I.; Chan, C. S.; Araki, T.; Terada, M.; Yamamoto, Y. Adv. Synth. Catal. 2009, 351, 1089.

(106) Sarbajna, A.; Pandey, P.; Rahaman, S. M. W.; Singh, K.; Tyagi, A.; Dixneuf, P. H.; Bera, J. K. ChemCatChem 2017, 9, 1397.

(107) Lin, C.-H.; Wang, Y.-J.; Lee, C.-F. Eur. J. Org. Chem. 2010, 2010, 4368 .

(108) Praveen, C.; Iyyappan, C.; Perumal, P. T. Tetrahedron Lett. 2010, 51, 4767 .

(109) Pouy, M. J.; Delp, S. A.; Uddin, J.; Ramdeen, V. M.; Cochrane, N. A.; Fortman, G. C.; Gunnoe, T. B.; Cundari, T. R.; Sabat, M.; Myers, W. H. ACS Catal. 2012, 2, 2182.

(110) Gabriele, B.; Salerno, G.; Fazio, A.; Pittelli, R. Tetrahedron 2003, 59, 6251.

(111) Bacchi, A.; Costa, M.; Della Cà, N.; Fabbricatore, M.; Fazio, A.; Gabriele, B.; Nasi, C.; Salerno, G. Eur. J. Org. Chem. 2004, 2004, 574.

(112) Della Ca, N.; Campanini, F.; Gabriele, B.; Salerno, G.; Massera, C.; Costa, M. Adv. Synth. Catal. 2009, 351, 2423.

(113) Fan, Y. C.; Kwon, O. Org. Lett. 2012, 14, 3264.

(114) Dell'Acqua, M.; Facoetti, D.; Abbiati, G.; Rossi, E. Tetrahedron

2011, 67, 1552 .

(115) Berg, T. C.; Bakken, V.; Gundersen, L.-L.; Petersen, D. Tetrahedron 2006, 62, 6121.

(116) Buxaderas, E.; Alonso, D. A.; Nájera, C. Adv. Synth. Catal. 2014, $356,3415$.

(117) Chahdoura, F.; Mallet-Ladeira, S.; Gomez, M. Org. Chem. Front. 2015, 2, 312 .
(118) Aronica, L. A.; Giannotti, L.; Tuci, G.; Zinna, F. Eur. J. Org. Chem. 2015, 2015, 4944.

(119) Fraser, R. R.; Renaud, R. N. Can. J. Chem. 1971, 49, 746.

(120) (a) Cignarella, G.; Savelli, F.; Sanna, P. Synthesis 1975, 1975,

252. (b) Cignarella, G.; Sanna, P.; Miele, E.; Anania, V.; Desole, M. S. J.

Med. Chem. 1981, 24, 1003. (c) Sanna, P.; Savelli, F.; Cignarella, G. J. Heterocycl. Chem. 1981, 18, 475.

(121) Ju, Y.; Varma, R. S. J. Org. Chem. 2006, 71, 135.

(122) Barnard, T. M.; Vanier, G. S.; Collins, M. J. Org. Process Res. Dev. 2006, 10, 1233.

(123) Subbarayappa, A.; Patoliya, P. U. Indian J. Chem., Sect B 2009, $48 B, 545$.

(124) Henderson, L.; Knight, D. W.; Williams, A. C. Synlett 2012, 23, 1667.

(125) Kobayashi, K.; Kondo, S.; Hashimoto, K.; Fukamachi, S.; Morikawa, O.; Konishi, H. Heterocycles 2007, 71, 1827.

(126) Mahdi, T.; Stephan, D. W. Chem. Eur. J. 2015, 21, 11134.

(127) Ogata, T.; Kimachi, T.; Yamada, K.-i.; Yamamoto, Y.; Tomioka, K. Heterocycles 2012, 86, 469.

(128) Cid, M. M.; Domínguez, D.; Castedo, L.; Vázquez-López, E. M. Tetrahedron 1999, 55, 5599.

(129) Fustero, S.; Ibáñez, I.; Barrio, P.; Maestro, M. A.; Catalán, S. Org. Lett. 2013, 15, 832.

(130) Clary, K. N.; Parvez, M.; Back, T. G. J. Org. Chem. 2010, 75, 3751.

(131) Wang, T.; Naredla, R. R.; Thompson, S. K.; Hoye, T. R. Nature 2016, 532, 484.

(132) Hashmi, A. S. K.; Frost, T. M.; Bats, J. W. J. Am. Chem. Soc. 2000, 122, 11553.

(133) (a) Hashmi, A. S. K.; Frost, T. M.; Bats, J. W. Catal. Today 2002, 72, 19. (b) Hashmi, A. S. K.; Salathé, R.; Frey, W. Chem. Eur. J. 2006, 12, 6991.

(134) Hashmi, A. S. K.; Weyrauch, J. P.; Kurpejović, E.; Frost, T. M.; Miehlich, B.; Frey, W.; Bats, J. W. Chem. Eur. J. 2006, 12, 5806.

(135) Hashmi, A. S. K.; Schäfer, S.; Bats, J. W.; Frey, W.; Rominger, F. Eur. J. Org. Chem. 2008, 2008, 4891.

(136) Hashmi, A. S. K.; Ghanbari, M.; Rudolph, M.; Rominger, F. Chem. Eur. J. 2012, 18, 8113.

(137) (a) Kotha, S.; Brahmachary, E.; Lahiri, K. Eur. J. Org. Chem. 2005, 2005, 4741. (b) Chopade, P. R.; Louie, J. Adv. Synth. Catal. 2006, 348, 2307. (c) Dominguez, G.; Perez-Castells, J. Chem. Soc. Rev. 2011, 40,3430 .

(138) Shibata, Y.; Tanaka, K. Synthesis 2012, 44, 323.

(139) Sun, Q.; Zhou, X.; Islam, K.; Kyle, D. J. Tetrahedron Lett. 2001, 42,6495 .

(140) Bonfield, E. R.; Li, C.-J. Adv. Synth. Catal. 2008, 350, 370.

(141) Liang, C.; Gu, L.; Yang, Y.; Chen, X. Synth. Commun. 2014, 44,

2416.

(142) Wu, W.; Zhang, X. Y.; Kang, S. X. Chin. Chem. Lett. 2010, 21, 18.

(143) Auvinet, A.-L.; Ez-Zoubir, M.; Vitale, M. R.; Brown, J. A.; Michelet, V.; Ratovelomanana-Vidal, V. ChemSusChem 2012, 5, 1888.

(144) Nishida, M.; Shiga, H.; Mori, M. J. Org. Chem. 1998, 63, 8606.

(145) (a) Sato, Y.; Nishimata, T.; Mori, M. J. Org. Chem. 1994, 59, 6133. (b) Sato, Y.; Nishimata, T.; Mori, M. Heterocycles 1997, 44, 443.

(146) Miwako, M.; Kayoko, K.; Nagisa, O.; Susumu, W. Chem. Lett. 1995, 24, 615.

(147) Aronica, L. A.; Albano, G.; Giannotti, L.; Meucci, E. Eur. J. Org. Chem. 2017, 2017, 955. 


\section{Biosketches}

\begin{tabular}{|l|l|} 
Laura Antonella Aronica (left) graduated cum laude in Chemistry in 1995 \\
from the University of Pisa. In 1999 she obtained her Ph.D. in Chemical \\
Sciences. During this period she spent six months as research assistant at \\
University of Ottawa with Prof. Howard Alper. She is presently a researcher at \\
the University of Pisa and her major research interests are concerned with \\
organometallic chemistry directed towards organic synthesis and in particular \\
with carbonylative cross coupling reactions and their application to the \\
synthesis of heterocyclic compounds. \\
Gianluigi Albano (right) studied Chemistry at the University of Pisa (Italy), where \\
he received his Master's Degree in February 2015. In November 2015 he started \\
his PhD studies at the same university, under the supervision of Prof. Lorenzo Di \\
Bari and Dr. Laura Antonella Aronica. His main research topics are focused on the \\
synthesis and characterization of chiral conjugated oligomers for innovative \\
optoelectronic applications and on the development of new protocols for the \\
synthesis of heterocyclic compounds through transition metals-promoted \\
reactions.
\end{tabular}

